\title{
LA GOBERNANZA ECONÓMICA DE LA UNIÓN DURANTE LA CRISIS: CONSECUENCIAS EN EL PROCESO DE INTEGRACIÓN'
}

\author{
Economic governance \\ of the European Union during the crisis: \\ Consequences for the process of integration
}

\author{
MARÍA LUZ MARTÍNEZ ALARCÓN \\ Universidad de Castilla-La Mancha \\ Luz.Martinez@uclm.es
}

\begin{abstract}
MARÍA GABRIELA LAGOS RODRÍGUEZ
Universidad de Castilla-La Mancha

Gabriela.Lagos@uclm.es
\end{abstract}

Cómo citar/Citation

Martínez Alarcón, M. L. y Lagos Rodríguez, M. G. (2017).

La gobernanza económica de la Unión durante la crisis: consecuencias en el proceso de integración.

Revista de Estudios Políticos, 176, 147-189.

doi: https://doi.org/10.18042/cepc/rep.176.05

\section{Resumen}

Este artículo pretende analizar las consecuencias de la nueva gobernanza económica de la Unión en el proceso de integración europea desde un punto de vista interdisciplinar y a partir de la regulación de la regla de la estabilidad presupuestaria. Desde el punto de vista jurídico, los nuevos desarrollos de la gobernanza económica europea han fortalecido el sesgo intergubernamental en el funcionamiento de la Unión en detrimento de la publicidad y transparencia y dificultando, en

1 Trabajo realizado en el marco del proyecto de investigación «Constitución y mercado en la crisis de la integración europea», I+D+i del Programa Estatal de Investigación, Desarrollo e Innovación orientada a los Retos de la Sociedad, del Ministerio de Economía y Competitividad (DER2013-48327-C3-1-R). Investigadores principales: José Luis García Guerrero y María Luz Martínez Alarcón. 
consecuencia, la rendición de cuentas. Todo ello en detrimento de la existencia de un poder europeo legítimo y limitado. Desde el punto de vista económico, la regla de la estabilidad presupuestaria, tal y como se ha configurado en su aplicación en un periodo de crisis económica, ha generado una pérdida de las convergencias de las economías y de la cohesión del territorio con el consiguiente riesgo de desintegración.

\title{
Palabras clave
}

Integración europea; crisis; gobernanza económica; consecuencias políticas y económicas.

\begin{abstract}
This article aims to analyze the consequences of the new economic governance of the European Union on the European integration process, from an interdisciplinary point of view. From the legal point of view, new developments in European economic governance have strengthened the inter-governmental approach typified by the Stability and Growth Pact at the expense of transparency and accountability, so much so that it becomes difficult to refer to a legitimate and limited European power. From the economic point of view, the current concrete implementation of the updated Fiscal Stability Treaty during a period of economic crisis has provoked a loss of convergence among Member State economies, impacting negatively on territorial cohesion.
\end{abstract}

Keywords

European integration; crisis; economic governance; political and economic consequences. 


\section{SUMARIO}

I. LA GOBERNANZA ECONÓMICA DE LA UNIÓN DURANTE LA CRISIS. II. CONSECUENCIAS POLÍTICAS DE LA REGLA DE ESTABILIDAD PRESUPUESTARIA. III. EL IMPACTO ECONÓMICO DE LA REGLA DE ESTABILIDAD PRESUPUESTARIA: 1. Incidencia en los ingresos públicos. 2. Incidencia en los gastos públicos. IV. CONCLUSIÓN: LA GOBERNANZA ECONÓMICA DE LA UNIÓN DURANTE LA CRISIS HA DEBILITADO LA INTEGRACIÓN POLÍTICA Y ECONÓMICA DE LA UNIÓN. BIBLIOGRAFÍA.

\section{LA GOBERNANZA ECONÓMICA DE LA UNIÓN DURANTE LA CRISIS}

Originariamente las Comunidades Europeas se plantearon como un área de libre comercio con el objetivo de incentivar el crecimiento económico de sus Estados, considerado requisito sine qua non de la estabilidad política de la zona. La viabilidad de esta nueva integración económica supranacional requería cohesión, y, en consecuencia, precisaba del acercamiento de las economías de los países miembros. Algo que se pone particularmente de relieve con la creación de la Unión Económica Monetaria (UEM), cuyo éxito dependía de la consecución de una convergencia sostenida en materia de estabilidad de precios, finanzas gubernamentales, tipos de cambio y tasas de interés a largo plazo. De esta forma, Maastricht trajo consigo la implantación de la regla de la estabilidad presupuestaria estableciendo unos techos de déficit y deuda públicos.

Recordemos que la discusión en torno a esta regla en sede europea comienza a mediados de los años ochenta del pasado siglo, cuando se proyectaba la moneda única, y que su explicitación se produce en el derecho primario de la Unión a través del artículo 104 C del Tratado de Maastricht (su protocolo anejo sobre el procedimiento aplicable en caso de déficit excesivo estableció que el déficit público no podía superar el $3 \%$ del PIB y que el nivel de endeudamiento público no podía superar el $60 \%$ del PIB). Más tarde, con ocasión de la puesta en marcha de la tercera fase de la UEM que debía producirse, a más tardar, el día 1 de enero de 1999 y que se traducía en la creación de la moneda única y de un Banco Central Europeo (BCE), el Tratado de Ámsterdam estableció un código de conducta fiscal común que se concretó en el Pacto de Estabilidad y Crecimiento (PEC), cuyo 
objeto, a través del reforzamiento de las reglas fiscales, consistía en garantizar una Hacienda Pública saneada en la zona euro a través de la prevención de incumplimientos, y de la reacción y corrección en su caso. El Pacto surgió en un momento económico favorable aunque pronto tuvo que pasar la prueba de su observancia cuando varió el ciclo y su aplicación exigió sacrificios presupuestarios a los Estados miembros ${ }^{2}$. Se arbitraron entonces procedimientos de déficit excesivo contra Irlanda y Portugal en los años 2001 y 2002, respectivamente. Sin embargo, Francia (en 2002) y Alemania (en 2003) incumplieron, sin consecuencias, el Pacto, generando su crisis ${ }^{3} \mathrm{y}$, finalmente, su reformulación en el año 2005 en un sentido flexibilizador (ampliación de los plazos, posible apreciación de circunstancias excepcionales y referencia al déficit a lo largo del ciclo) ${ }^{4}$.

Esta situación, sin embargo, no se prolonga por mucho tiempo. La crisis económica en Europa ha traído consigo, entre otras cosas, una intervención particularmente incisiva de las instituciones europeas que ha condicionado - y sigue condicionando- de forma decisiva las políticas económicas de los Estados miembros, y, en particular, ha traído consigo el reforzamiento de la regla de la estabilidad presupuestaria y una fuerte resistencia - que en ocasiones cede ante la evidencia aunque siempre de forma tímida 5 - frente a cualquier posibilidad de interpretar o aplicar con flexibilidad el cumplimiento de dicha regla contenida hoy en el artículo 126 del Tratado de Funcionamiento de la Unión Europea (TFUE) desarrollado por el Protocolo 12, sobre el procedimiento aplicable en caso de déficit excesivo. En efecto, el Six-Pack (2011) y el Two-Pack (2013), que implican una nueva reforma del PEC, y el Tratado de Estabilidad, Coordinación y Gobernanza (TECG, 2013, informalmente Pacto Fiscal Europeo ${ }^{6}$ ) han endurecido las exigencias y procedimientos derivados de la regla de la estabilidad presupuestaria ${ }^{7}$. Asimismo, este tratado

2 Una crítica del pacto por no contemplar de manera diferenciada los requerimientos de la estabilidad presupuestaria en situaciones de expansión o de recesión económica en Esparza (2012: 157).

3 Pese a la propuesta de la Comisión, el Consejo suspendió los procedimientos de déficit excesivo contra Francia y Alemania y no adoptó ningún acuerdo al respecto. El Tribunal de Luxemburgo dirimió el conflicto entre la Comisión y el Consejo en la Sentencia de 13 de julio de 2004 (asunto C-27/04).

4 Una evolución detallada del derecho europeo en la materia en Miguel Bárcena (2011).

5 La flexibilización ha venido por la vía de ampliar los plazos inicialmente previstos para la consecución de los objetivos de déficit.

6 Sobre sus antecedentes y procedimiento de elaboración, véase Bar (2012: 80-82).

7 En este sentido, los jefes de Estado y de Gobierno de la zona euro se comprometieron, en su declaración del 9 de noviembre de 2011, entre otras cosas, a que los presupuestos 
obligaba a sus veinticinco Estados firmantes — del mismo se descolgaron Reino Unido y República Checa, y tampoco ha sido firmado por Croacia- a incorporar al más alto nivel normativo la "regla del equilibrio presupuestario" durante un plazo que se prolongaba hasta el 1 de enero de $2014^{8}$. De hecho, la recepción de préstamos procedentes del Mecanismo de Estabilidad Europeo (MEDE) quedaba condicionada a que el Estado interesado hubiera introducido en la legislación nacional la regla que exige un presupuesto equilibrado antes del 1 de marzo de 2014.

La Unión Europea, pues, para superar la crisis económica, ha decidido poner el acento, tras la adopción de unas primeras y efímeras medidas de estímulo de la economía que no produjeron el resultado esperado, habida cuenta la magnitud de la crisis, en el desarrollo de una política presupuestaria centrada en el saneamiento, en tiempo récord, de las cuentas públicas y que se concreta, por un lado, en una reducción y control del gasto público que ha recibido el calificativo de austericida por parte de los sectores más críticos ${ }^{9}, \mathrm{y}$, por otro, en un incremento de la presión impositiva (en ambos casos, con diferencias sustanciales entre Estados). Y todavía hoy esta, la política presupuestaria vía estabilidad, continúa siendo el elemento que la Unión considera nuclear para superar la crisis y fortalecer la integración económica. Eso sí, se ha complementado — sin abandonarla - con una serie de medidas que han reforzado la integración financiera de la Unión ${ }^{10}$. En este sentido debe

de sus administraciones públicas estuvieran equilibrados o con superávit. El principio se consideraba respetado si, por norma general, el déficit estructural anual no excedía del 0,5\% del PIB nominal. El artículo 3 TECG, cuya entrada en vigor se produjo el 1 de enero de 2013, concreta esta previsión.

8 Al respecto se ha afirmado que el TECG condiciona el propio poder constituyente de la zona euro. Si en un primer momento la constitucionalización de las reglas fiscales europeas obedeció a razones políticas más o menos espontáneas según los casos (reforma de la LFB de 2009 o reforma del artículo 135 CE en 2011), a raíz del TECG ha venido a institucionalizarse jurídicamente (Medina, 2014: 192). La petición de modificar ab interno y "preferiblemente» al máximo nivel normativo la disciplina presupuestaria de los Estados miembros supuso una solución inédita y ha provocado un efecto paradójico al permitir que la Unión Europea «entre por la ventana» en las Constituciones nacionales (Balaguer, 2012: 343).

9 Se expresaron críticas contra la concreta configuración de la regla de la estabilidad presupuestaria por lo que podía suponer en términos de coste para el Estado social en Martínez (2013).

10 Tres han sido las fases de respuesta de la Unión Europea desde que estallara la crisis. Primera: respuesta de tipo keynesiana que concluye en el año 2010 (la prioridad fue asegurar la cooperación entre los bancos centrales para evitar el colapso del sistema 
mencionarse la reforma del artículo 136 TFUE que ha conducido al fin de la genérica y estricta prohibición del bailout, sobre la que se había articulado parcialmente la disciplina fiscal de los Estados de la zona euro en virtud de lo dispuesto en el artículo 125 TFUE y que da cobertura a la creación de ciertos mecanismos de asistencia financiera ${ }^{11}$. Finalmente, queda pendiente una necesaria armonización fiscal sobre la que poco se ha avanzado en el ámbito de la imposición directa — no en la indirecta, como veremos.

Ahora bien, como pretendemos demostrar en este trabajo, los desarrollos de la gobernanza económica de la Unión durante la crisis, que han puesto el acento en el saneamiento de las cuentas públicas de los Estados miembros, no han traído consigo el fortalecimiento del proceso de integración europea, ni en lo político, ni en lo económico, ni, en consecuencia, en lo social. En primer lugar, porque las novedades en la materia representan un cambio de tendencia que está afectando a la arquitectura institucional de la Unión, y, a su través, a la naturaleza constitucional del proyecto, a su democraticidad y consiguiente legitimidad. Y, en segundo lugar, porque el análisis de las respuestas que han dado los Estados miembros buscando el equilibrio de las cuentas públicas demostrará que estas no han corregido los problemas económicos de la Unión entendida en su conjunto, ni, en particular, han conducido a una mayor cohesión entre los Estados afectados por su aplicación.

financiero europeo y promover planes de estímulo). Segunda: caracterizada por el protagonismo de la consolidación fiscal (en este caso violentando los lazos de preferencias de los Gobiernos y las demandas de la ciudadanía, lo que solo es posible hacer en el corto plazo). Tercera: se acompaña la estabilidad presupuestaria, sin abandonarla, de un mayor activismo en política monetaria desde el verano de 2012 (mayor activismo del BCE e intento de acelerar y fortalecer el programa de integración, centrado en la creación de una unión bancaria con la puesta en marcha de políticas monetarias «no convencionales») (Fernández, 2014).

11 La Decisión del Consejo Europeo de 25 de marzo de 2011 modifica el artículo 136 TFUE (DOUE L 91 de 6.4.2011). Añade el siguiente apartado tercero al precepto: «Los Estados cuya moneda es el euro podrán establecer un mecanismo de estabilidad que se activará cuando sea indispensable para salvaguardar la estabilidad de la zona euro en su conjunto. La concesión de toda ayuda necesaria con arreglo al mecanismo se supeditará a condiciones estrictas». Dicha reforma sirvió para poner en marcha el MEDE. Dos trabajos excelentes sobre las políticas de rescate y el papel desempeñado por el BCE, que habría conducido a una radicalización del carácter heterodoxo (no convencional) de sus políticas en Menéndez (2012 y 2015). Al respecto mencionaremos, como uno de los últimos hitos, la sentencia del TJUE que ha avalado, si bien con condiciones, el programa de compra de deuda pública por parte del BCE — Sentencia Gauwailer (C-64/14). 


\section{CONSECUENCIAS POLÍTICAS DE LA REGLA DE ESTABILIDAD PRESUPUESTARIA}

Todos sabemos que la denuncia sobre el déficit democrático en la adopción de las decisiones en la Unión Europea es un tema recurrente, presente desde la misma constitución de las Comunidades Europeas. El sesgo intergubernamental fue el protagonista en los momentos iniciales de su funcionamiento, con sus consiguientes implicaciones tanto en lo relativo a las instituciones que en su seno iban a desempeñar el papel decisor como en lo relativo a los procedimientos de adopción de las decisiones y las mayorías requeridas para adoptarlas. Como se ha dicho, la democracia, simplemente, no formó parte de la versión original del proyecto ${ }^{12}$. Originariamente, las decisiones de las Comunidades Europeas se tomaban en el seno de un Consejo que, en función del tipo de materias, podía decidir por unanimidad — vía intergubernamental—, pero también por mayoría simple o cualificada — vía supranacional—, si bien finalmente se impuso, y por mucho tiempo, la vía intergubernamental ${ }^{13}$. El Consejo

12 En este sentido, Weiler (2011: 686), Porras (2012: 127).

13 Se generalizó la utilización de la regla de la unanimidad para la adopción de las decisiones de todas las políticas comunitarias del Consejo (con la posibilidad, pues, de que un solo Estado pudiera vetar una decisión no compartida), y ello aun a pesar de que los tratados preveían la mayoría cualificada para la adopción de las decisiones en el Consejo con relación a determinadas materias (en tales casos la Comisión asumía una relevante función política de impulso —a través de su monopolio de iniciativay se alcanzaba cierto equilibrio entre los intereses nacionales - representados por el Consejo- y el interés europeo — representado por la Comisión-). Ahora bien, Francia no aceptó que el Consejo adoptara decisiones por mayoría en cuestiones que pudieran afectar a sus intereses nacionales «vitales» y estalló la denominada crisis de la silla vacía (1965): sus representantes dejaron de participar en las principales reuniones comunitarias exigiendo una revisión del rol de la Comisión y de la regla de la mayoría. La presión francesa dio lugar al Compromiso de Luxemburgo de 1966, una resolución política del Consejo de Ministros con la que los Estados miembros pactaron — contra lo dispuesto en el Tratado CEE - renunciar al voto por mayoría en favor de la unanimidad cuando estuvieran en juego intereses nacionales «muy importantes». Finalmente, la unanimidad se generalizó y se aplicó a todas las decisiones del Consejo con independencia del carácter vital o no de los intereses implicados. Así pues, desde 1966 y durante algo más de veinte años, bastó con que un representante del Consejo, del COREPER o de un grupo de trabajo en el Consejo expresase una reserva a la propuesta en discusión para que esta, o bien quedase paralizada, o bien se modificase de acuerdo con los deseos del país que había amenazado con el veto (la cosa se complicó con la ampliación de 1973; los intereses de los nuevos Estados —Gran Bretaña, Irlanda y Dinamarca - a menudo no coincidían con los intereses del resto de 
funcionaba de espaldas a principios básicos del sistema democrático como la transparencia y la publicidad, sin posibilidad, pues, de hacer posible la rendición de cuentas (ni en el nivel comunitario ni en el nivel nacional). Las predecesoras del Parlamento Europeo, la Asamblea común de la CECA (1951) y la Asamblea parlamentaria de la CEE y de la CEEA (1957), tenían atribuidas competencias muy limitadas de tipo consultivo y de control político, y esto solo se podía mantener en un contexto de cesión muy limitada de competencias desde los Estados a la organización supraestatal.

Así que el recorrido hacia delante del proceso de integración europea, con la progresiva asunción de ámbitos materiales cada vez de mayor relevancia (al menos hasta Maastricht ${ }^{14}$ ), debía, necesariamente, en la medida en que sus participantes eran Estados constitucionales, venir acompañado por cambios sustanciales institucionales y procedimentales. En este sentido, hemos asistido a sucesivas modificaciones del derecho originario que, al menos hasta la crisis, han venido reforzando el sesgo supranacional de la organización a través de una transformación importante tanto de los participantes como de los procedimientos utilizados para la adopción de sus decisiones. Más precisamente, las sucesivas

socios comunitarios). Por cierto, el origen del Consejo Europeo se explica atendiendo a dicho contexto. Desde diciembre de 1974 comenzaron a celebrarse reuniones periódicas de los jefes de Estado y presidentes del Gobierno con el objeto de impulsar políticamente la construcción europea a través de la solución, en su seno, de los asuntos más conflictivos o de aquellos en los que el Consejo no hubiera conseguido la unanimidad (Areilza, 2014: 36-38).

14 La UEM supuso una transferencia completa a la Unión de la decisión sobre la política monetaria, un símbolo crucial de la soberanía nacional y hasta entonces un instrumento doméstico de la política macroeconómica. Además, la UEM limitó el alcance de las políticas presupuestarias nacionales introduciendo la regla de la estabilidad presupuestaria vinculante. Por otro lado, Maastricht marcó el paso de una comunidad económica a una unión política. Sin embargo, al mismo tiempo, las disputas entre el Reino Unido y la mayoría de los países sobre la UEM y sobre el Protocolo Social de Maastricht mostraron que cualquier extensión adicional de competencias legislativas en el marco de la gobernanza económica podía, potencialmente, provocar la desintegración de la Unión recientemente constituida. De hecho, los Tratados de Ámsterdam y Niza no tocaron la materia. Finalmente, las negociaciones del Tratado Constitucional y del Tratado de Lisboa revelaron que no habría hueco para transferencias adicionales de competencias a favor de la Unión en un futuro previsible. En particular, el debate sobre la finalidad del proceso de integración y las llamadas a una definición clara de las competencias de la Unión y de los Estados sugerían que los gobiernos de los Estados miembros creían que el proceso de integración ya había alcanzado un nivel muy alto (Puetter, 2012: 167). 
modificaciones del derecho originario de la Unión trajeron consigo un Parlamento transformado que habría abandonado la posición absolutamente secundaria que le atribuyeron los tratados constitutivos en los años cincuenta del siglo pasado de tal forma que, en la actualidad, y con relación a muchos ámbitos (pero no todos), podemos afirmar que participa de forma decisiva, junto con el Consejo, en la conformación de la voluntad de la Unión, y que lo hace en una relación de igualdad con respecto al mismo en aquellas decisiones que son consecuencia de la utilización del procedimiento legislativo ordinario, caracterizado por su transparencia. Asimismo, se generalizó, a partir de la aprobación del Acta Única Europea, la aplicación de la regla de la mayoría para adoptar decisiones en el Consejo en los supuestos que así lo preveían, diluyendo de esta forma el poder de los Gobiernos de los Estados miembros considerados individualmente que, a partir de ese momento, podían ver cómo una decisión concreta podía salir adelante en la Unión a pesar de su oposición frontal a la misma (si bien, de facto, se ha constatado la pervivencia de la práctica de la cultura del consenso como regla general para la adopción de las decisiones en su seno ${ }^{15}$ ).

Ahora bien, el avance general de la dimensión supranacional en la organización y funcionamiento de la Unión con anterioridad al estallido de la crisis nunca condujo a la renuncia de su dimensión intergubernamental entendida en sentido fuerte. Habría que tomar al respecto en consideración, por ejemplo, que el papel del Parlamento Europeo en el proceso decisional de la Unión no se ha equiparado al del Consejo, en particular (aunque no solamente ${ }^{16}$ ) en lo relativo a la política económica; o el hecho de que, en

15 Al respecto, García (2015: 363-364). Los largos estudios preparatorios en el COREPER, las dinámicas de dobles lecturas y la ubicuidad de la Comisión están encaminados a propiciar el consenso y evitar a toda costa situar a uno o a varios Estados en el imaginario de la minoría política. En todo caso, si algún Estado quedara relegado, la democracia supranacional no dejaría de ofrecerle garantías (garantías jurídicas — recurso de legalidad—; garantías políticas — principio de subsidiariedad—; garantías normativas — reserva de directivas-) (Azpitarte, 2014: 321).

16 El Consejo ejerce funciones de definición de políticas y de coordinación en las condiciones establecidas en los tratados (artículo 16.1 TUE), y, como regla general, su peso será mayor que el del Parlamento en el marco de los procedimientos legislativos especiales (muy significativos desde un punto de vista cuantitativo y cualitativo). Además, los tratados prevén procedimientos específicos de adopción de decisiones no legislativas que no son susceptibles de producir «actos legislativos» con relación a determinadas materias en los que el protagonismo reside, también, en el Consejo. En tales casos, el Parlamento pasa a desempeñar funciones de tipo consultivo (véase los arts. 74, 103, 109 TFUE). O pensemos en casos en los que, sencillamente, desaparece cualquier participación de la institución parlamentaria (véanse los arts. 43.3, 70, 122.1, 342 TFUE). Hay que tener en cuenta, 
las sucesivas modificaciones del derecho originario de la Unión tras el Acta Única Europea, que trajo consigo la superación del Compromiso de Luxemburgo, haya emergido siempre un debate fundamental, más o menos encubierto, sobre el reparto y la ponderación de votos en el Consejo. El resultado final ha sido un Consejo dominado por los países más poblados (Alemania, Francia, Reino Unido e Italia) ${ }^{17}$, en especial por Alemania, que va consiguiendo imponer - no sabemos por cuánto tiempo habida cuenta los resultados obtenidos con sus recetas- los elementos de la nueva gobernanza económica, los ritmos para su consecución y la distribución de los costes.

En particular, el ámbito económico es uno de los ámbitos considerados especialmente sensibles por los Estados miembros y estos se resisten sistemáticamente a ceder parcelas de soberanía en la materia a la Unión, aun a pesar del crecimiento de la interdependencia en dicho campo y de la necesidad de encontrar respuestas a retos que solo se pueden afrontar con expectativas de éxito de forma común. Tampoco Lisboa supuso una nueva transferencia formal de competencias decisionales al nivel comunitario en materia económica, aunque lo cierto es que los desarrollos de la gobernanza económica de la Unión de la crisis orientados a garantizar la solidez de la zona euro han debilitado, todavía más (pues la restricción de las facultades de actuación autónoma de los gobiernos nacionales era un hecho con anterioridad a la crisis), las facultades de los Estados de la Unión de desarrollo, ejecución y fiscalización de sus políticas económicas, $y$, en especial, de sus políticas económicas presupuestarias ${ }^{18}$. Los

igualmente, que el Parlamento Europeo ocupa una posición absolutamente secundaria en el ámbito de la Política Exterior y de Seguridad Común. Sin olvidar que el Consejo —y la Comisión - puede desempeñar funciones normativas de ejecución previa autorización a través del derecho derivado de la Unión.

17 La pérdida de peso de los países más pequeños en el Consejo se ha intentado compensar con la instauración de la práctica «un miembro en la Comisión por Estado». Sobre el proceso hasta llegar a este Consejo dominado por los países más poblados, véase Areilza (2014: 51-54).

18 Menéndez (2012: 64-69) destaca los nuevos poderes en materia de política fiscal que ha adquirido la Unión como consecuencia: i) de la mayor densidad normativa y el mayor número de objetivos de política fiscal sujetos a coordinación; ii) de la naturaleza cuasi automática de la imposición de sanciones en caso de incumplimiento como consecuencia de la radical transformación de las reglas de voto para la apertura de procedimientos de control y aplicación de sanciones (muchas de las decisiones fundamentales sobre las políticas fiscal y macroeconómica de los países de la eurozona se adoptan ahora, a propuesta de la Comisión, por una mayoría 
desarrollos europeos con relación a la política fiscal no responden a principios de coordinación ni se articulan a través de instrumentos de soft law, como en principio así ocurre en el terreno de la política económica de la Unión. No lo hacían antes (si bien es cierto que la concreción normativa original del PEC y su posterior reforma en 2005 lo revelaron como un conjunto normativo esencialmente simbólico) y lo hacen aún menos con ocasión de la crisis económica, cuyos desarrollos normativos han traído consigo un refuerzo importantísimo del grado de vinculatoriedad de los compromisos sobre el límite del déficit y de la deuda pública que deben respetar los Estados miembros ${ }^{19}$. La cesión de parcelas de poder estatal en este ámbito de la gobernanza económica de la Unión ha sido subrayada por muchos (sin alternativa, al menos, por lo que hace a los Estados

cualificada inversa); iii) de la creación del Semestre Europeo, cuya entrada en vigor se produjo a través del Six-Pack, en concreto a través del Reglamento 1175/2011, del Parlamento Europeo y del Consejo, de 16 de noviembre de 2011, y que supone una mutación radical en materia de coordinación de las políticas fiscales y macroeconómicas, ya que el procedimiento supranacional se impone frente al nacional. El Semestre opera al amparo de la regla de la mayoría cualificada inversa y exige que el proyecto de presupuestos que los gobiernos lleven ante sus Parlamentos nacionales se corresponda con el que ha sido sometido a consideración previa de la Comisión y el Consejo, lo que en definitiva condiciona y constituye un decisivo control ex ante de las decisiones nacionales en materia de política fiscal; iv) de la coordinación macroeconómica, pues dos de los reglamentos del paquete de reforma de la gobernanza económica, de facto, confieren a la Unión nuevos poderes que con toda probabilidad supondrán la asignación efectiva de competencias a la misma (véase, al respecto, el trabajo de Carrera, 2013, sobre el Procedimiento de Prevención y Corrección de los Desequilibrios Macroeconómicos). Martínez Lago constata, con relación al Semestre Europeo, que este procedimiento habría traído consigo, por una parte, la limitación de la función de dirección política que compete a los gobiernos nacionales en la medida en que condiciona notablemente el proceso de elaboración de los presupuestos nacionales antes de que se presenten para su debate parlamentario, y, por otra, un debilitamiento de la función presupuestaria del Parlamento nacional consistente en el debate y aprobación del presupuesto (Martínez Lago, 2013: 156).

19 La Unión Europea de la crisis habría pasado de una gobernanza «blanda» a una gobernanza «dura», ya que el nuevo PEC no solo se caracteriza por el aumento de la densidad normativa de sus contenidos sino que, además, el salto de la mayoría cualificada a la mayoría cualificada inversa para la imposición de sanciones en caso de incumplimiento — que las convierte en cuasi automáticas - ha traído consigo la superación del carácter puramente simbólico de las sanciones del anterior pacto (Menéndez, 2012: 82-83). 
deudores que deben asumir tales compromisos si pretenden contar con el soporte del MEDE). A este respecto, el TECG representa uno solo de los elementos, de momento su cénit, de una cadena más larga de intervenciones europeas durante la crisis, dirigidas a reforzar la regla de la estabilidad presupuestaria. Su artículo 3.2 obliga a incorporar las obligaciones contenidas en su apartado primero al derecho nacional de las partes contratantes mediante disposiciones que tengan fuerza vinculante y sean de carácter permanente, preferentemente de rango constitucional, o cuyo respeto o cumplimiento estén de otro modo plenamente garantizados a lo largo de los procedimientos presupuestarios nacionales ${ }^{20}$.

En todo caso, se sigue observando una fuerte resistencia por parte de los Estados a perder el control de la materia en el nivel supranacional. Y ello se manifiesta tanto en el fenómeno producido de arrinconamiento del denominado «método comunitario» en favor del «método de la Unión», este último basado en pactos entre diferentes Estados fuera del marco del derecho comunitario, como en una superación, en un determinado sentido, de los elementos institucionales y procedimentales que regularon la dimensión económica de la Unión en Lisboa.

Con relación al primer asunto, y aunque es cierto que la Unión ha hecho uso de los canales jurídicos e institucionales del método comunitario durante la reforma de la gobernanza económica de la Unión (pensemos en el Six-Pack y en el Two-Pack) ${ }^{21}$, también lo es que algunas de las iniciativas supraestatales más importantes sobre el tema se han recogido en instrumentos normativos propios del derecho internacional, por consiguiente, fuera del derecho de la Unión Europea (en este sentido, el TECG o el MEDE, si bien por diferentes

20 En todo caso, no todos los Estados partían de la misma situación con relación a esta obligación de prever la regla del equilibrio presupuestario al más alto nivel normativo, ni mucho menos todos han recurrido a la reforma constitucional para incorporar dicha regla al más alto nivel normativo. Es más, la mayor parte de los países de la eurozona ha recibido y dado actuación a esta obligación contenida en el TECG a través de leyes ordinarias. Sobre el proceso de incorporación de la regla al más alto nivel normativo en distintos Estados, véase Frosina (2015: 494-521). En el número monográfico 165 de la Revista de Estudios Políticos, coordinado por López Castillo y Closa Montero, también se pueden consultar varios estudios que describen cómo los países signatarios del TECG han ido incorporando la regla a sus ordenamientos nacionales.

21 Aunque estos canales e instrumentos del método comunitario han venido influenciados por negociaciones paralelas en cuerpos intergubernamentales que han condicionado los resultados alcanzados dentro del procedimiento legislativo ordinario (Chiti y Teixeira, 2013: 688). 
motivos en cada caso ${ }^{22}$ ), al menos de forma temporal (recordemos que el artículo 16 TECG prevé la futura incorporación de su contenido en el derecho de la Unión $\left.{ }^{23}\right)$. La Sentencia Pringle, que ha avalado tanto el procedimiento de creación del MEDE como su contenido, ha dado soporte a la creación de este tipo de estructuras jurídico-políticas paralelas a la Unión, potenciando así el intergubernamentalismo ${ }^{24}$. En efecto, este cambio en los instrumentos legales para afrontar la crisis implica sustraer las decisiones sobre esta materia a las instituciones europeas y atribuirlas a los Estados miembros, más precisamente, a sus Ejecutivos (aunque es cierto que su contenido final repercute en la actuación de las instituciones europeas ${ }^{25}$ ). Este recurso al derecho internacional ha suscitado, entre determinados sectores doctrinales, una honda preocupación en la medida en que puede poner en cuestión principios fundamentales del proceso de integración europea ${ }^{26}$.

$22 \mathrm{Al}$ respecto, Craig (2014: 25).

23 En cuanto al origen y consolidación del «método de la Unión» nos remitimos a Chiti y Texeira (2013: 685 y ss.) y Areilza (2014: 111 y 143-150). Este último autor ha advertido de que: «No es seguro que se trate de un periodo transitorio en el que el intergubernamentalismo se ha impuesto debido a la situación de emergencia económica que dará lugar en su momento a una reforma de los tratados...» (2014: 148-149). La solución internacional permitió, por otra parte, superar sin (demasiados) daños el desacuerdo del Reino Unido y de la República Checa y evitó, en virtud de la previsión del tratado estableciendo que entrará en vigor solo con la adhesión de al menos doce de sus miembros (art. 14.2), cualquier forma de veto por parte de los Estados miembros, que, como sabemos, constituye la espada de Damocles en todo proceso de ratificación de los tratados, incluido Lisboa (Benvenuto, 2015: 98). Véase, igualmente, Martín (2012: 403-408).

24 Azpitarte (2014: 320-321).

25 Por ejemplo, en el MEDE, la Comisión, el BCE y el FMI evaluarán el riesgo para la estabilidad financiera de la zona euro y analizarán la sostenibilidad de la deuda pública del país que solicitó la ayuda. O, en el marco del TECG, la Comisión desempeña funciones muy relevantes de fiscalización y sanción.

26 Von Bogdandy e Ioannis (2014). Se ha denunciado que el control de la aplicación del MEDE tras la Sentencia Pringle por parte del Tribunal de Luxemburgo no está sirviendo para verificar el cumplimiento por parte del MEDE del derecho de la Unión. Por una parte, el Tribunal está utilizando la doctrina Pringle como cita recurrente para inaplicar la Carta de los Derechos Fundamentales de la Unión. Pero es que, además, en el caso de los Memorandos de Entendimiento, el Tribunal de Justicia tiende a eximir de responsabilidad a las instituciones de la Unión señalando que estas - Comisión, $\mathrm{BCE}$ - no tienen poder de decisión propio en el marco del MEDE y que los Memorandos son responsabilidad exclusiva del MEDE (organismo internacional) (Aguilar, 2015). 
Y, con relación a la segunda cuestión, el cambio de los elementos institucionales y procedimentales que regularon la dimensión económica de la Unión en Lisboa también se ha traducido en un refuerzo de la dimensión intergubernamental de la política de la Unión relativa a la estabilidad de las cuentas públicas, tanto en el marco decisional como en el relativo a su implementación y su fiscalización.

Las decisiones que la Unión ha ido adoptando al respecto se han canalizado a través de la actuación del Consejo Europeo y del Consejo (Europa de los Veintiocho) y de las Eurocumbres y el Eurogrupo, que se han consolidado como una nueva estructura institucional de la eurozona (Europa de los Diecinueve $)^{27}$. Las dos últimas instancias han desempeñado un papel preponderante en las decisiones relacionadas con la crisis de deuda soberana, $y$, en general, en la elaboración de las respuestas europeas a la crisis y han actuado aisladas de cualquier tipo de influencia procedente de las instituciones políticas de la Unión no intergubernamentales. Recordaremos, brevemente, que los Estados de la zona euro, con una coordinación especialmente intensa, se organizan a través del Eurogrupo ${ }^{28}$ y de las Eurocumbres ${ }^{29}$, y que ello permite

27 No vamos a detenernos en este trabajo, aunque no se puede pasar por alto, en la intervención en dicho ámbito de estructuras nuevas en las que han participado actores externos a la Unión — pensemos en el FMI a través de la troika-y que ha permitido hablar de una Unión del rescate. O en la emergencia, como actores fundamentales en esta crisis, de otras instituciones europeas de naturaleza "presuntamente» más técnica, en particular el BCE y el TJUE.

El Eurogrupo, colegio de ministros de Economía y Finanzas de los países que forman parte de la eurozona (artículo 137 TFUE y Protocolo 14 anejo al Tratado de Lisboa), ha adquirido mucho poder y autonomía frente al Consejo de Economía y Finanzas (ECOFIN), en el que están representados todos los Estados miembros, y ha intentado también despegarse de la Comisión. «Ha dado pasos para crear sus propias estructuras, aprovechando su reconocimiento jurídico por el Tratado de Lisboa y el apoyo francés para consolidar una Unión de dos velocidades. En esta división, basada en los que están dentro y los que quedan fuera del euro, el núcleo director queda en manos de un mecanismo intergubernamental» (Areilza, 2014: 149-150). Se ha consolidado una convención constitucional según la cual solo los nacionales de los Estados miembros de la eurozona son elegibles para ciertos puestos de responsabilidad en las instituciones europeas (presidente del Consejo Europeo, presidente de la Comisión y comisario de Asuntos Económicos y Monetarios) (Menéndez, 2012: 80).

29 Las eurocumbres, reuniones de jefes de Estado y de gobierno de los países de la eurozona (con la asistencia del presidente de la Comisión y eventualmente el del BCE), fueron impulsadas por el presidente francés N. Sarkozy hasta que finalmente han quedado institucionalizadas en el artículo 12 TECG (su trabajo se desarrolla atendiendo a unas informales Normas para la organización de los trabajos de las cumbres 
diferenciar entre dos ámbitos de la gobernanza económica de la Unión: la que afecta a los Estados que forman parte de la zona euro y la que afecta a aquellos otros que se mantienen ajenos a la misma, lo cual plantea un reto en la medida en que a través de dicha distinción existe la posibilidad de debilitar la unidad institucional y legal de la Unión Europea generando inconsistencias en el sistema ${ }^{30}$.

En la Unión de los Veintiocho, el Consejo Europeo, reforzado por el Tratado de Lisboa, que lo contempla como institución de primer orden y le atribuye numerosas e importantes facultades, ha asumido, de facto, un papel político predominante con la crisis de la moneda común en cuanto que órgano que marca el rumbo político y resuelve, en última instancia, las situaciones de crisis o bloqueo institucional (aunque el derecho primario de la Unión confiere al Consejo el papel decisor al respecto). Este órgano ha condicionado intensamente la iniciativa de la Comisión, la adopción de las decisiones en el Consejo y ha reducido las posibilidades de participación del Parlamento Europeo ${ }^{31}$.

del euro). La definitiva juridificación de las cumbres del euro ha traído consigo un Consejo Europeo informal que se ha convertido en un serio competidor para el Consejo Europeo de la Unión.

30 Chiti y Texeira (2012: 696-697). Aunque otros autores han apuntado que el reforzamiento de la asimetría que ha generado la gobernanza económica de la crisis puede haber introducido la flexibilidad necesaria para permitir avances (Martinico, 2014: 258-259).

31 Elías (2015: 42-50) presenta al Consejo y a la Comisión como órganos cuasi ejecutivos del Consejo Europeo al que define, junto con el BCE, como el otro gran protagonista de la crisis. Entre las actuaciones que reflejan la posición destacada del Consejo Europeo, antes, y sobre todo después, de la crisis: resolución sobre el PEC de 1997 proporcionando a los Estados miembros, al Consejo y a la Comisión orientaciones políticas para aplicarlo y alentando a los Estados miembros a seguir políticas presupuestarias; modificación del artículo 136 TECG, fruto de la Decisión 2011/199/CE, de 25 de marzo de 2011 (reforma que validó la Sentencia Pringle - sentencia TJUE, asunto C-370-12, Thomas Pringle/Government of Ireland-); Resolución de 27 de diciembre de 2013, por la que acuerda profundizar en la unión económica en dos direcciones (con la aprobación de un nuevo pacto fiscal y el reforzamiento de la coordinación de la política económica; y con el desarrollo de instrumentos de estabilización — promoción de la puesta en marcha del MEDEpara afrontar los desafíos a corto plazo); en diciembre de 2012, el Consejo Europeo, apoyándose en el «Plan director para una Unión Económica y Monetaria profunda y auténtica. Apertura de un debate europeo» que presentó la Comisión en noviembre de 2012, definió los pasos a seguir para reforzar la UEM. Su protagonismo ha sido valorado de forma mayoritariamente negativa por la doctrina por su marcado 
Por otra parte, el derecho primario de la Unión confiere al Consejo la facultad para decidir sobre un cambio o desarrollo de la regulación de esta materia (las posiciones se fijan en el seno del ECOFIN, que cuenta con el soporte técnico del Comité Económico y Financiero para el desarrollo de sus trabajos). El artículo 126.14 TFUE le atribuye la competencia para sustituir, en su caso, el protocolo sobre el procedimiento aplicable en caso de déficit excesivo, por unanimidad y con arreglo a un procedimiento legislativo especial que exige la consulta previa del Parlamento Europeo y del Banco Central Europeo. Asimismo, el Consejo, a propuesta de la Comisión y previa consulta al Parlamento Europeo, fijará las normas de desarrollo y definiciones para la aplicación de las disposiciones del protocolo mencionado.

El Consejo, además, en virtud de lo dispuesto en el artículo 136 TFUE, es el órgano que decide sobre la adopción de las medidas que garanticen el correcto funcionamiento de la UEM siguiendo el procedimiento contemplado en el artículo 126 TFUE (se excluye la aplicación del 126.14 TFUE que, como acabamos de ver, contempla un procedimiento especial para la sustitución o desarrollo del Protocolo aplicable en caso de déficit excesivo). Entre ellas, decide sobre las medidas que sean precisas para reforzar la coordinación y supervisión de su disciplina presupuestaria. Únicamente participarán en las votaciones para la adopción de alguna de estas medidas los miembros del Consejo que representen a los Estados miembros cuya moneda es el euro. La mayoría cualificada se definirá de conformidad con la letra a) del apartado 3 del artículo 238. Finalmente, también es el Consejo el órgano que determina las posiciones comunes ad extra de la Unión Europea con relación al euro, con propuesta de la Comisión y del BCE (artículo 138 TFUE).

La intervención del Parlamento Europeo y de la Comisión, las instituciones que, en principio, deben representar la pluralidad ideológica de la ciudadanía europea y el interés general de la Unión, es muy limitada en el ámbito decisional de la política económica de la Unión vinculada a la UEM. En particular en lo que hace a la Eurocámara, pues, al fin y al cabo, la Comisión aporta un soporte técnico de relevancia que condiciona $-\mathrm{o}$

carácter intergubernamental. Aunque no todos han realizado tal valoración. Por ejemplo, Puetter, 2012, que atribuye al método de trabajo en el Consejo Europeo el calificativo de «intergubernamentalismo deliberativo», defiende su papel entendiendo que, gracias a su flexibilidad, se habría convertido en la sede propicia para afrontar problemas imprevistos y necesitados de una ágil y eficiente labor de coordinación. 
puede llegar a condicionar- la adopción de las decisiones de las instituciones europeas intergubernamentales (Consejo Europeo, y, sobre todo, Consejo). En efecto, el Parlamento Europeo no ha desempeñado función directora alguna y tampoco su deliberación política al respecto ha sido central. Lo cierto es que se limita a elevar una preceptiva consulta previa al Consejo en los casos en que adopta, por unanimidad, una decisión sobre una eventual sustitución del protocolo sobre el procedimiento aplicable en caso de déficit excesivo, o en aquellos otros en los que el consejo fija las normas de desarrollo y definiciones para la aplicación de las disposiciones de dicho protocolo. No se prevé, sin embargo, su intervención, en la adopción de medidas para garantizar el correcto funcionamiento de la UEM (medidas para reforzar la coordinación y supervisión de la disciplina presupuestaria), ni en la fijación de las posiciones comunes ad extra de la Unión Europea con relación al euro, decisiones todas ellas que se concretan en el Consejo. Y ello aún a pesar de que haya pasado a desempeñar cierto papel en el procedimiento del Semestre Europeo en la medida en que ha logrado asegurarse el derecho a participar en los diálogos económicos introducidos por el Six-Pack. A su través, se permite al Parlamento Europeo mantener debates con las otras instituciones de la Unión y con representantes nacionales sobre temas económicos y ejercer de alguna forma su función de control político y exigencia de rendición de cuentas ${ }^{32}$. También puede llegar a ser relevante su papel en el ámbito de la cooperación interparlamentaria (véase el artículo 13 TECG).

Con relación a la tarea de fiscalización de la política fiscal europea, esta compete al Consejo y a la Comisión. Ambos colaboran en la tarea de supervisión del cumplimiento de los compromisos asumidos por los Estados miembros en materia de déficit público. Puede tratarse de un control de tipo preventivo (cuando se detectan riesgos de incumplimiento) o de tipo reactivo con el objeto de corregir los efectos de un incumplimiento ya producido. De cualquier modo, el Consejo tiene la última palabra sobre si existe o no un riesgo de incumplimiento o sobre si se ha producido o no un incumplimiento. La Comisión, tras una labor de fiscalización, elaborará un informe con sus recomendaciones y el Consejo, previo dictamen del Comité Económico y Financiero sobre el informe de la Comisión, decidirá sobre la existencia o no de riesgo de incumplimiento o sobre la existencia o no de

32 Destacando la presencia del Parlamento Europeo en la gobernanza económica de la Unión, tanto en el ámbito del PEC (política monetaria) como en el Procedimiento de Prevención y Corrección de los Desequilibrios Macroeconómicos (PDM, política económica), a través de estos diálogos económicos (Carrera, 2013). 
incumplimiento. El Consejo es también la institución que adopta las medidas previstas en el TFUE para reaccionar frente a dichas situaciones, de nuevo, sobre la base de las recomendaciones de la Comisión (véase el artículo 126, apartados 2 a 14, ambos inclusive, TFUE).

Ahora bien, la labor de la Comisión en el ámbito de la fiscalización de la implementación de las decisiones fiscales de la Unión por parte de los Estados miembros no es en absoluto desdeñable, en particular, debido a la radical transformación de la regla de voto en el Consejo - mayoría cualificada inversa- para la adopción de importantes decisiones en el marco del Pacto que introdujo el Six-Pack ${ }^{33}$. De hecho, tras unos primeros momentos en los que la doctrina denunció una debilitación del papel de la Comisión en el proceso de la gobernanza económica de la Unión durante la crisis, comienza a ser habitual consultar trabajos en los que tal afirmación se matiza señalando que, aunque, en efecto, la Comisión ha visto muy mermada su actividad de impulso y decisional en la política económica de la UEM, también ha adquirido un peso sin precedentes en lo relativo a las facultades de fiscalización, y sanción en caso de incumplimiento, de los compromisos asumidos por parte de los Estados miembros ${ }^{34}$.

Frente a ello, la participación del Parlamento Europeo es también muy limitada en el procedimiento de fiscalización del cumplimiento de las obligaciones sobre déficit y deuda pública. Su intervención presenta una naturaleza meramente informativa y se produce en las etapas finales del procedimiento, en determinados supuestos en los que el Consejo adopta medidas contra el Estado miembro incumplidor. El artículo 126.11, in fine,

33 La mayoría cualificada inversa, o de rechazo, dificulta enormemente el rechazo de las recomendaciones de la Comisión en el Consejo (ibid., 91-93).

34 En este sentido Elías (2015: 51-54). Un análisis detallado sobre la posición de la Comisión durante la crisis, que concluye en el mismo sentido, en Closa (2014: 8388). De Areilza Carvajal habla de las competencias inauditas que el TECG otorga a la Comisión cuando somete los presupuestos nacionales a su aprobación, aunque reconoce que la crisis del euro ha traído consigo una pérdida de la capacidad de iniciativa y de voz de la Comisión a favor tanto del Consejo Europeo como del Consejo. A su juicio, el papel político secundario de la Comisión durante la crisis del euro se ha debido a la falta de liderazgo en su seno, y, en buena medida, a la actitud de los gobiernos más poderosos sobre la misma. Para Alemania, la Comisión debe ejecutar las decisiones del Consejo Europeo, muchas de ellas sugeridas por Berlín. Para Francia, la Comisión no debe entrometerse en áreas tradicionales reservadas a los Estados y que con el rediseño del euro se han europeizado rápidamente (presupuestos nacionales, reformas del estado de bienes, competitividad...) (Areilza, 2014: 31). 
del TECG establece que: «El Presidente del Consejo informará al Parlamento Europeo acerca de las decisiones tomadas». El papel del Parlamento Europeo queda así muy limitado en esta segunda fase de control de la ejecución de las decisiones políticas presupuestarias de la Unión si lo comparamos con la relevancia de la función que la Comisión realiza al respecto y a la que ya hemos hecho referencia.

Para la doctrina, pues, es posible hablar de una «desparlamentarización» en el ámbito de la Unión ${ }^{35}$. En general, en materia económica, y en particular, en las políticas presupuestarias de la crisis, el Parlamento Europeo tiene muy poco que decir, ya sea respecto al diseño de los mecanismos ya en cuanto al cumplimiento de los objetivos. Una lectura detenida del derecho de la crisis, y en particular del TECG y del Six-Pack, no deja lugar a dudas sobre la posición marginal del Parlamento Europeo en la gobernanza económica de la Unión Europea, y ello a pesar de sus intentos destinados a conseguir un peso político significativo en esta parcela ${ }^{36}$. Es preciso advertir, de cualquier modo, que la Eurocámara tampoco desempeñaba un papel relevante en el anterior PEC; aún más, se podía considerar que su papel resultaba menos relevante que el asumido en la actualidad en la medida en que, en el Pacto de 1997, reformado en 2005, el nombre de la institución ni siquiera se mencionaba. Ahora bien, en aquel momento, la débil vinculación del PEC para los Estados miembros no planteaba, al menos no en los preocupantes términos en los que hoy se plantea habida cuenta el contexto de estricta vinculatoriedad de los compromisos derivados del TECG, el problema de la falta de implicación del Parlamento Europeo en la gobernanza económica de la Unión ${ }^{37}$.

35 Closa (2014: 88-91). Sobre la frágil participación del Parlamento Europeo y de los Parlamentos nacionales en la gobernanza económica de la Unión, Embid (2012: 137 y 141-142). Por otra parte, mientras que el Parlamento Europeo y los Parlamentos nacionales se han visto limitados a desempeñar un papel de ratificación de las medidas concertadas en el ámbito supranacional e internacional, se constata un lento pero inexorable proceso de «jurisdiccionalización" de los conflictos políticos y de las demandas sociales (Poli, 2015: 582-583).

36 Véase, al respecto, Fasone (2012).

37 Martinico (2014: 255-256), siguiendo a Fasone (2012). Estos compromisos no admiten hoy derogaciones, excepto por circunstancias excepcionales. Comparado con el pasado, los avisos y sanciones se han convertido en semiautomáticos (los avisos y sanciones propuestos por la Comisión se van a adoptar a menos que los rechace una mayoría cualificada en el Consejo). Además, la coordinación de la política económica se ha convertido también en vinculante con el Semestre Europeo. 


\section{EL IMPACTO ECONÓMICO DE LA REGLA DE ESTABILIDAD PRESUPUESTARIA}

Desde mediados del siglo pasado, las aportaciones teóricas de Mundell ${ }^{13} \mathrm{y}$ de Kenen ${ }^{39}$ respecto a las consecuencias de políticas fiscales flexibles en una zona monetaria ya advertían de la necesidad de una disciplina fiscal común como condición para estabilizar la economía en un área monetaria única. En ausencia de esta política fiscal común, el resultado esperado sería el que la crisis de 2008 ha puesto de relieve: déficits públicos y acumulación de deuda. Como predijeron algunos autores sobre el futuro de la moneda única europea ${ }^{40}$, la ausencia de las condiciones necesarias para poder hablar de un área monetaria óptima provocó un shock asimétrico, generando déficit presupuestarios y ajustes severos en empleo y salarios en algunos países de la UEM. Como respuesta a estos desequilibrios económicos, la Unión dispuso recursos adicionales para estos Estados ${ }^{41}$, y en contrapartida por la recepción de estas ayudas se han exigido fuertes recortes del gasto y la reordenación de las finanzas públicas, como muestra la tabla 1 , en la que mostramos el impacto de la crisis en el sector público de los Estados miembros de la UEM ${ }^{42}$ y en el de la totalidad de los Estados de la Unión.

38 Mundell analizó cuáles serían los efectos de un área de integración económica y monetaria para los países europeos. A su entender, debían concurrir una serie de condiciones esenciales para lograr un área monetaria óptima. A saber: i) un alto grado de apertura comercial entre los países de la zona; ii) una elevada movilidad de factores; iii) un alto grado de diversificación de las economías implicadas; iv) una autoridad que permitiera un control de los shocks asimétricos de la demanda (Mundell, 1961: 657-665).

39 Este autor puso de manifiesto que en presencia de una política monetaria única y de políticas fiscales flexibles se producen actuaciones fiscales descompensadas por parte de los gobiernos implicados (Kenen, 1969: 41-60).

40 A título de ejemplo, Jonung y Drea (2009).

41 En el año 2010 se pusieron en marcha dos instrumentos de ayuda financiera a los Estados miembros de la Unión Monetaria: el Mecanismo Europeo de Estabilidad Financiera (MEEF) y el Fondo Europeo de Estabilidad Financiera (FEEF), ambos provisionales. En 2012, y tras la correspondiente reforma del artículo 136 TFUE, se creó un instrumento permanente de ayuda financiera: el Mecanismo Europeo de Estabilidad (MEDE). Los Estados que han recibido financiación del programa de asistencia financiera de la Unión han sido Chipre, Grecia, Hungría, Irlanda, Letonia, Portugal, Rumanía y España.

42 A datos de 2016, los países integrantes de la UEM son Alemania, Austria, Bélgica, Chipre, Eslovaquia, Eslovenia, España, Estonia, Finlandia, Francia, Grecia, Irlanda, Italia, Letonia, Lituania, Luxemburgo, Malta, Países Bajos y Portugal. 
Tabla 1. Evolución de los indicadores del sector público, 2010/2014

\begin{tabular}{|c|c|c|c|c|c|}
\hline Euro área (19) ${ }^{(1)}$ & $2010^{(2)}$ & 2011 & 2012 & 2013 & 2014 \\
\hline PIB (pm) & 9.185 .699 & 9.800 .426 & 9.835 .192 & 9.993 .499 & 10.108 .253 \\
\hline Saldo presupuestario & -570.801 & -407.770 & -359.705 & -294.436 & $-260.927,0$ \\
\hline Gasto público (\% PIB) & 51,0 & 49,1 & 49,7 & 49,6 & 49,4 \\
\hline Ingreso Público (\% PIB) & 44,8 & 44,9 & 46,1 & 46,6 & 46,8 \\
\hline Deuda Pública (\% PIB) & 85,5 & 86,0 & 89,3 & 91,1 & 92,1 \\
\hline UE- 28 & 2010 & 2011 & 2012 & 2013 & 2014 \\
\hline PIB (pm) & 12.337 .092 & 13.180 .889 & 13.431 .023 & 13.547 .545 & 13.955 .563 \\
\hline Saldo presupuestario & -803.120 & -597.078 & -573.413 & -445.217 & -418.885 \\
\hline Gasto público (\% PIB) & 50,6 & 48,6 & 49,0 & 48,6 & 48,2 \\
\hline Ingreso Público (\% PIB) & 44,1 & 44 & 44,8 & 45,3 & 45,2 \\
\hline Deuda Pública (\% PIB) & 79,9 & 81 & 83,8 & 85,5 & 86,8 \\
\hline
\end{tabular}

(1) En los datos agregados que ofrecemos es preciso considerar la inclusión de dos Estados - Letonia (2014) y Lituania (2015) — que no formaban parte de la UEM en el periodo de referencia. Eurostat actualiza la información estadística con su incorporación, siendo esta la disponible para realizar el presente estudio.

(2) Información del año 2010 extraída de Eurostat (2014).

Fuente: elaboración propia a partir de Eurostat (2015b).

El primer elemento significativo que debemos destacar es el reducido incremento del PIB en ambos grupos de Estado, con tasas reducidas durante los años 2011 a 2013 y con un ligero repunte en el ejercicio 2014 ${ }^{43}$. En segundo lugar, la contribución de la zona euro al PIB comunitario es muy significativa (el $72 \%$ del total en el año 2014), lo cual era de esperar ya que este grupo lo integran los Estados con las economías más desarrolladas ${ }^{44}$. Por sí mismo, este dato muestra la importancia de los aspectos financieros y monetarios en la crisis económica de la Unión, pudiendo afirmar que el impacto ha sido mayor en los Estados que han asumido la moneda única.

Como reacción al reducido incremento del PIB, y ante la imposibilidad de aplicar una política monetaria diferenciada, la mayoría de los Estados integrantes de la Unión acordaron reforzar su coordinación económica y

43 Para mayor detalle puede consultarse Eurostat (2015a).

44 Según datos de Eurostat, en 2014 las economías de Alemania, Reino Unido, Francia, Italia y España representaron el 71,4\% del PIB de la UE-28. 
presupuestaria. Los Estados con dificultades financieras que se han implicado en este proceso de refuerzo han podido acceder a financiación adicional procedente de la Unión, pero las ayudas percibidas han exigido la asunción de fuertes recortes del gasto público y la reordenación de las finanzas públicas. Los costes sociales de estas medidas son conocidos $^{45}$, así como los riesgos de desestabilización política en los Estados más afectados por la crisis y el cuestionamiento social del concepto de Europa. Se hace patente que estamos ante consecuencias de la crisis financiera y económica muy relevantes para el mantenimiento de una cierta cohesión que permita el crecimiento económico y la mejora de las condiciones de vida de su población.

Sabemos que la crisis trae causa en problemas de naturaleza financiera, pero también deriva de deficiencias estructurales tanto de las economías nacionales como de la propia integración económica del territorio de la Unión. Dejando al margen los problemas financieros, existe un consenso relativo a que la respuesta a la crisis exige realizar reformas estructurales que permitan una convergencia de las economías de los Estados miembros ${ }^{46}$, pero, por otro lado, se sigue poniendo el acento en la sostenibilidad de las finanzas públicas, cuyos desbalances determinaron el incremento del precio de su financiación externa ${ }^{47}$. La cuestión es cómo hacer compatibles ambos objetivos: obtener los

45 Casi el 25\% de la población europea está en situación de pobreza y riesgo de exclusión social. La distribución no es homogénea y encontramos que los Estados con peor comportamiento son los más castigados por la crisis: España —29,2\%—, Grecia -36\%—, Malta — 23,8\%—, Italia - 28,1\%—, Chipre - 27,4\%— y Portugal $-27,5 \%$ - empeoran de 2008 a 2014. Véase Eurostat (2015d).

46 Las diferencias en el precio de los factores productivos — capital, propiedad, trabajo, tecnología y conocimiento- son la causa de las dificultades económicas de algunos Estados. Algunas de estas diferencias derivan de la coyuntura económica del momento, pero los más importantes tienen su origen en las deficiencias en el diseño y funcionamiento de instituciones básicas de la economía. Frente a estos problemas estructurales se requieren cambios profundos y significativos que suelen presentar un elevado coste socioeconómico pero que son insoslayables para su corrección. Un buen ejemplo de este problema es la pérdida de competitividad de la economía española en el periodo de referencia, con un coste elevado del factor trabajo que llevó al desempleo a buena parte de la población activa de nuestro país.

47 El Informe Anual del Mecanismo de Estabilidad Europea para el año 2014 señala estas dos cuestiones como «lecciones que podemos extraer de la crisis»: «A corollary from the previous two lessons is that prudent fiscal policy and structural reforms are complementary. In the face of fears of low future growth, so-called secular stagnation, budgetary sustainability will result in higher and more stable long-run growth only if accompanied by structural reforms», European Stability Mechanism (2014): Annual Report, 12. 
recursos necesarios para reformar las economías y al tiempo reducir el déficit público y, además, en un contexto de crecimiento escaso, nulo o negativo. La vinculación entre los problemas de competitividad y déficit resulta evidente al identificar a los Estados que peor han soportado la crisis financiera y que, por tanto, han tenido más dificultades en generar recursos. El dilema de los gobernantes de estos Estados estriba en contraer el gasto - y en tal caso, tenderán a reducir el que menor impacto político tenga, esto es, el destinado a inversión- o en incrementar el ingreso para evitar el déficit y financiar las reformas necesarias. Cabe incluso plantearse una cierta prelación entre ambos objetivos de forma que la cuestión es a qué atendemos primero, a la estabilidad de las cuentas públicas o a financiar las reformas necesarias para mejorar la competitividad.

La relevancia de este asunto es crucial en el contexto de una Unión Económica que se sustenta en la convergencia de los territorios. Sin esa aproximación de las economías de los Estados miembros se socava tanto la eficiencia del modelo como su legitimidad. Una aproximación simple al tema podría concluir que el modelo está en equilibrio con áreas - Estados- que producen y otras que compran lo que los primeros hacen, pero si algo ha puesto de relieve la crisis es que una drástica reducción de la renta disponible en los países consumidores implica su sobreendeudamiento, la caída de sus indicadores económicos y el empobrecimiento de su población, así como ajustes consecuentes en los países productores, tanto en la minoración de sus ventas como en su papel de financiadores de deuda.

En este contexto, nos planteamos qué incidencia ha tenido la regla de estabilidad presupuestaria en la corrección de los problemas económicos que pretendían evitarse. ¿Muestran los datos mayor integración económica entre los Estados que se han visto afectados por su aplicación? De ser así, habría que aceptar que la imposibilidad de incurrir en déficit ha sido una medida adecuada, más allá de los importantes costes que ha supuesto su implantación. Debe quedar claro que la intervención que plantea la regla de estabilidad se limita a imponer a los Estados una restricción sobre el resultado final de sus finanzas, sin prescribir el modo en que cada país actúe para asegurar tal resultado. En función de necesidades y preferencias particulares, cada Estado decidirá si hace mayor hincapié en la disciplina del gasto público o si trata de incrementar los recursos impositivos que recauda. No se trata de opciones excluyentes, como es obvio, pero sí marcarán una diferencia sustancial en el proceso de evitar el déficit. Así, cabe suponer que una política de disciplina de gasto tendrá una incidencia directa sobre los ciudadanos de rentas medias y bajas, más dependientes de la provisión de bienes y servicios del sector público, $y$, por el contrario, un incremento de los impuestos se dirigirá a los contribuyentes de mayor capacidad contributiva, sin despreciar a una clase media más 
numerosa y con menos posibilidades de eludir la carga fiscal. Es necesario reconocer que las medidas adoptadas por cada Estado para asegurar su observancia tendrán consecuencias no menores sobre el conjunto de los agentes de cada economía e influirán también en las condiciones sociales del país, pero nuestra intención es, ahora, analizar qué decisiones han tomado los Estados miembros de la Unión Monetaria para hacer efectiva esta regla y cuál ha sido su repercusión en la situación económica del país y sobre la cohesión del territorio de la Unión ${ }^{48}$.

\section{INCIDENCIA EN LOS INGRESOS PÚBLICOS}

Desde la perspectiva de los ingresos públicos, el impacto de la crisis económica ha tenido consecuencias trascendentales para los sectores públicos de los países europeos. La situación de déficit severo en las cuentas públicas ha provocado medidas contractivas de la actividad pública, y, a la par, un renovado interés por la integración fiscal, plasmada no ya en una armonización tal como la define el TFUE, sino en una auténtica unificación de ciertos aspectos de la fiscalidad, en especial, el referido al tratamiento del capital. El cambio observado en la actitud de los Estados miembros no responde a un súbito impulso armonizador justificado en la bondad de su aplicación; antes bien, es la consecuencia de un análisis minucioso de las fuentes de ingresos de los erarios públicos y de las vías de fuga de estos recursos. Hoy, los Estados europeos son conscientes, por razón de necesidad, de que la falta de progreso en la armonización fiscal implica la existencia de un espacio de ejercicio para la competencia fiscal entre los países miembros que, como veremos, se traduce en una pérdida general de los ingresos recolectados por las haciendas.

El gráfico 1 muestra una tendencia creciente en la evolución de los ingresos, tanto en el caso de los países miembros de la Unión como en el caso de los pertenecientes a la UEM. De hecho, los ingresos crecen más en la eurozona (2 puntos sobre el PIB) que en la Unión de los Veintiocho $(1,2)$. El gráfico demuestra, pues, que los Estados han hecho un esfuerzo en la consecución de ingresos impositivos, pese a la situación de crisis económica de Europa.

48 Se elige el periodo comprendido entre 2008 y 2014 porque permite apreciar el cambio en las decisiones fiscales de los Estados por efecto de la crisis. Respecto al año de inicio, hemos tomado el primero para el que tenemos series homogéneas adaptadas a la incorporación de Letonia (2014) y Lituania (2015) al conjunto de los países con el euro como moneda. Por su parte, en la mayor parte de los casos, la información estadística consultada ofrece como últimos datos disponibles los correspondientes al ejercicio 2014. 


\section{Gráfico 1. Evolución de los ingresos fiscales de los Estados de la UE/UEM}

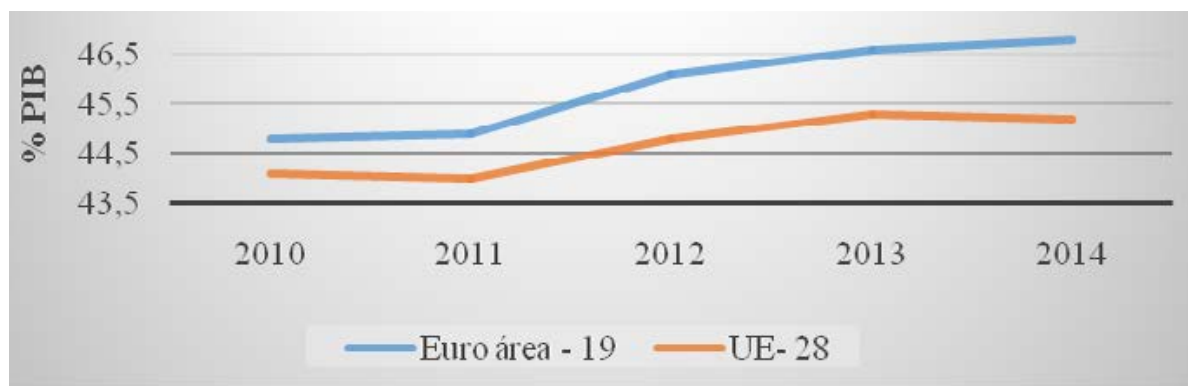

Fuente: elaboración propia a partir de Eurostat (2015b).

El ajuste de las cuentas públicas ha supuesto un incremento de la presión fiscal sobre los sujetos pasivos y las operaciones económicas en el territorio europeo, en especial, en la zona euro. Esta realidad no solo tiene consecuencias ad intra, al favorecer comportamientos oportunistas de contribuyentes que elijan Estados de menor tributación, sino que también afecta a la competitividad del territorio europeo en un contexto de economía globalizada: Europa tiene una tasa de gravamen elevada [la media de la UE-28 es el $40 \%$ del PIB para el año 2014, muy por encima de los Estados Unidos (26\%) y Japón $(30 \%)$, y la presión fiscal es todavía mayor en la zona euro $(41,5 \%$ del PIB) $]^{49}$.

La mayor parte de los ingresos percibidos por los Estados europeos proceden de los impuestos - en torno al $90 \%$ del total, incluyendo las contribuciones sociales-. No obstante, la crisis económica también ha provocado modificaciones en la estructura impositiva y en el volumen de recaudación obtenida $^{50}$. Algunos de esos cambios, en especial el aumento de la presión sobre las rentas personales, dificultan el acceso al empleo y desincentivan la incorporación al mercado laboral. La estructura de la imposición sobre el trabajo, que comprende tanto las cotizaciones sociales de empresarios y trabajadores como el impuesto sobre la renta personal, varía de manera considerable entre todos los países de la Unión. Así, la suma de ambos conceptos supone un 22,2\% del PIB de media ponderada para la UE-28 y un 23,8\% para la UE-18 en el año 2012. Los Estados de reciente incorporación presentan una baja fiscalidad por este concepto y, dentro de los países más

49 Eurostat (2016b).

50 Los datos referidos a la fiscalidad de la UE han sido extraídos de Unión Europea (2014). 
antiguos, algunos tienen mayores aportaciones del impuesto (Dinamarca, Irlanda, Reino Unido y Suecia) y otros de las cotizaciones sociales (Alemania, Francia y Holanda). La carga impositiva sobre estas rentas menos móviles ha soportado los efectos de la crisis, especialmente en los Estados de la Unión Monetaria. La media ponderada del tipo de gravamen alcanza el $46,6 \%$ para la UE-28 en 2014, aunque el tipo de gravamen varía considerablemente dentro de la Unión (desde un mínimo del $10 \%$ en Bulgaria a más del $55 \%$ en Suecia, Portugal y Dinamarca).

Los impuestos que recaen sobre el capital suponen un 8,2\% del PIB en 2012, con tendencia a incrementar su peso. Uno de sus componentes, el gravamen sobre la renta de sociedades mercantiles, ha experimentado una reducción desde mediados de la década de los noventa, alcanzando el 2,6\% del PIB en 2012. El tipo efectivo medio de gravamen apenas supera el $20 \%$ (21,1\% para 2013), aunque también se produce la conocida variabilidad en el seno de la UE-28 (desde el $9 \%$ de Bulgaria al 34,3\% de Francia). La fiscalidad sobre las empresas es un ámbito susceptible a la competencia fiscal y el tipo de gravamen reducido suele ser una manifestación de esta política de atracción de inversiones y actividad económica. Irlanda estableció su tipo de gravamen societario en un $12,5 \%$ como medida de lucha contra la crisis económica. Pese a las críticas y conminaciones del resto de los Estados mantuvo esta decisión, logrando que algunas de las mayores multinacionales que operan en Europa hayan designado a este país como sede de su domicilio fiscal. La tendencia homogeneizadora se manifiesta en la reciente propuesta de directiva Anti Tax Avoidance Directive ${ }^{51}$, que recoge una serie de normas básicas contra las prácticas elusivas que afectan al funcionamiento del mercado interior. La propuesta de Directiva traslada al ámbito de la UE el contenido del Proyecto OCDE/G20 de BEPS ${ }^{52}$ de lucha contra la erosión de la base imponible y el traslado de beneficios que se presenta a fines del año 2015. El objetivo es evitar los efectos perjudiciales que estas operaciones pueden entrañar para las administraciones tributarias, favoreciendo la elusión de bases imponibles y la deslocalización de beneficios mediante el establecimiento de un precio convenido mayor o menor —según interese- al correspondiente del mercado. Según datos de la propia OCDE, las pérdidas ocasionadas a los erarios públicos se estiman entre un 4 y un $10 \%$ de la recaudación global que debería recogerse en concepto de Impuesto sobre Sociedades en el mundo - entre 100 y 240 millones de dólares americanos

51 Comisión de las Comunidades Europeas (2016).

52 OECD (2015). 
por año-. Por su parte, el gravamen sobre el capital ${ }^{53}$ sigue una tendencia similar de crecimiento moderado. La carga efectiva que soporta el capital se encuentra entre el 20 y el $35 \%$ del PIB de cada Estado, para la mayoría de ellos.

Por último, la fiscalidad del consumo es el ámbito en el que hay mayor grado de homogeneidad normativa dada la asunción del Impuesto del Valor Añadido (IVA) como general y obligatorio en toda la Unión. Además, otros impuestos sobre consumos específicos también se someten a normativa europea, por lo que el grado de armonización de la fiscalidad indirecta es alto, a diferencia de lo que ocurre con la imposición directa. Aproximadamente dos terceras partes de la imposición sobre el consumo corresponde al IVA, que representa el 7,9\% del PIB para el conjunto de los Estados de la Unión. Este impuesto experimentó una caída importante de su recaudación en los dos ejercicios posteriores a la crisis, corregida en parte porque a partir de 2009 su tipo de gravamen se ha incrementado en la mayoría de los Estados miembros (la media se sitúa en el $21,5 \%$ en 2014). No obstante, la existencia de fraude y la incidencia de la economía sumergida es un grave problema para este tributo, que muestra una diferencia sustancial entre la recaudación teórica y la real, estimándose en un 1,5\% del PIB. En algunos Estados, esta diferencia se ha incrementado de manera notable desde el inicio de la crisis en 2008 (es el caso de España, Grecia, Letonia, Irlanda, Portugal y Eslovaquia).

En definitiva, el comportamiento de los Estados europeos en estos últimos años evidencia un esfuerzo en el incremento de la recaudación con dos ámbitos fundamentales de acción: el gravamen sobre las rentas derivadas del trabajo y la fiscalidad indirecta. Una interpretación general de esta tendencia debe hacerse considerando que la explicación de la misma se encuentra en la necesidad de solventar déficit presupuestarios, ya que no es la recomendada por la teoría económica en la fase contractiva del ciclo ni recomendable para los políticos que la aplican y deben someterse a reelección.

\section{INCIDENCIA EN LOS GASTOS PÚBLICOS}

Con relación al comportamiento de los gastos públicos, el gráfico 2 muestra una tendencia contraria a la descrita para el caso de los ingresos, pues se experimenta un descenso del gasto de las administraciones públicas en

53 Recoge los impuestos que gravan los ingresos procedentes del ahorro, las inversiones de los hogares y las sociedades y la carga fiscal asociada a los depósitos de capital derivados del ahorro y la inversión de ejercicios anteriores. 
torno a dos puntos porcentuales sobre el PIB de cada grupo. Asimismo, se constata que el proceso de contracción del gasto público ha sido más intenso en la UE-28 que el que registra la zona euro:

\section{Gráfico 2. Evolución del gasto de los Estados de la UE/UEM}

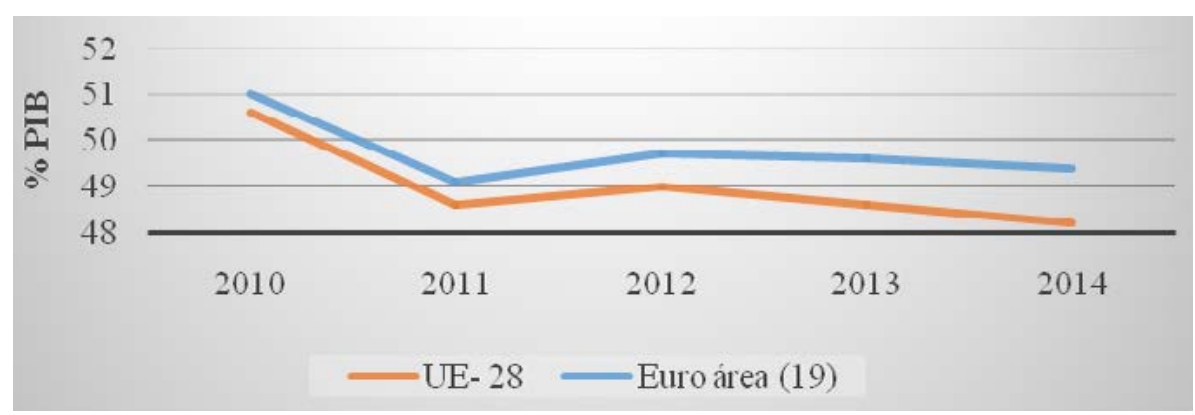

Fuente: elaboración propia a partir de Eurostat (2015b).

Estamos, de nuevo, ante un comportamiento coherente con el objetivo de limitar el déficit de las haciendas nacionales, pero no acorde al ciclo económico: lo esperable en condiciones de crisis económica es que el gasto del sector público crezca para hacer frente a la demanda de gasto social que sigue a una caída de la renta disponible de los ciudadanos. Este gasto social no se compone únicamente por las transferencias por desempleo, sino que engloba el coste de provisión de bienes públicos, cuya demanda crece, así como el coste de la prestación de servicios públicos que compensan la pérdida de capacidad económica de los individuos. Por tanto, más allá de la consideración de los datos globales, será necesario matizar los efectos de dicho descenso considerando la información desagregada por Estado para el año 2014. La tabla que sigue pone de relieve la variabilidad del comportamiento de cada país, con referencias extremas que van desde el casi $35 \%$ de gasto respecto al PIB de Rumanía al $57 \%$ de Dinamarca.

Los Estados que han reducido su gasto respecto al ejercicio 2008 son Rumanía (-12\%), Lituania (-9\%), Irlanda (-8\%), Reino Unido (-6\%) y Estonia (-4\%). Para el resto de los Estados, la tendencia es creciente, destacando los incrementos de Chipre (26\%), Finlandia (20\%), Eslovaquia, Eslovenia, Bulgaria y Portugal (14\%) y Dinamarca (10\%). España ha ido reduciendo su ritmo de incremento del gasto público desde el $17 \%$ que experimentó en 2012 - frente al realizado en 2008- hasta un $8 \%$ en 2014. En definitiva, podemos observar cómo la resistencia a la reducción 
LA GOBERNANZA ECONÓMICA DE LA UNIÓN DURANTE LA CRISIS: CONSECUENCIAS... 175

Tabla 2. Gasto público de la UE/UEM

y Estados miembros en porcentaje del PIB, 2014

\begin{tabular}{llll}
\hline \multicolumn{1}{c}{ EU-28 } & \multicolumn{2}{c}{$\mathbf{4 8 , 2}$} \\
\hline EA-19 & \multicolumn{4}{c}{$\mathbf{4}$} \\
\hline Estado miembro & $\mathbf{2 0 1 4}$ & Estado miembro & $\mathbf{2 0 1 4}$ \\
\hline Dinamarca & 56,9 & Alemania & 44,3 \\
\hline Finlandia & 58,3 & Luxemburgo & 42,4 \\
\hline Francia & 57,5 & Malta & 44,0 \\
\hline Bélgica & 55,1 & Rep. Checa & 42,6 \\
\hline Austria & 52,7 & España & 44,5 \\
\hline Suecia & 51,8 & Reino Unido & 43,9 \\
\hline Italia & 51,2 & Polonia & 42,1 \\
\hline Hungría & 49,9 & Eslovaquia & 41,6 \\
\hline Grecia & 49,9 & Bulgaria & 42,1 \\
\hline Portugal & 51,7 & Estonia & 38,0 \\
\hline Eslovenia & 49,8 & Letonia & 37,1 \\
\hline Croacia & 48,2 & Irlanda & 38,2 \\
\hline Holanda & 46,2 & Lituania & 34,8 \\
\hline Chipre & 49,3 & Rumanía & 34,9 \\
\hline
\end{tabular}

Fuente: elaboración propia a partir de Eurostat (2016a).

del gasto público da como resultado el crecimiento del gasto en términos absolutos $^{54}$. Los datos disponibles muestran que el gasto en protección

54 También se producen cambios en su composición, sobre todo en los países en los que la presión sobre su deuda soberana ha generado costes elevados de intereses y de amortización de la misma. Así, en el ejercicio 2013, España presenta un nivel de endeudamiento del 93,6 \% de su PIB, Irlanda del 123,7 \%, Portugal del $129 \%$ y Grecia del 175,1\%, respecto al objetivo de convergencia de Maastricht fijado en un máximo del $60 \%$ (Banco Central Europeo, Statistisc. Goverment Finances). La carga de la deuda pública sobre su PIB supone, para el 
social es el más importante en los presupuestos de los Estados miembros, suponiendo más del $40 \%$ del gasto total que realizan ${ }^{55}$. La distribución por país ofrece información muy relevante en cuanto al peso y distribución de su población activa: así, hay países que registran mayor gasto en pensiones por jubilación (Italia, Luxemburgo o Austria), mientras que otros tienen un gasto relevante en subsidios por desempleo (Irlanda y España). Por funciones, la partida siguiente en importancia es el gasto en sanidad o salud, acercándose al $15 \%$ del total del gasto de media en ambos grupos considerados. Esta sencilla y rápida aproximación al gasto social nos permite constatar el esfuerzo que los Estados han hecho en este periodo para tratar de mantener el nivel de provisión pública, siendo al tiempo una de las explicaciones de esa resistencia al descenso más intenso del gasto global de las administraciones públicas.

Dentro del gasto público, merece la pena tratar brevemente el capítulo de inversión, que ha sido considerado como clave para el crecimiento económico de un territorio y se ha utilizado por parte de los Gobiernos como un instrumento para crear las condiciones idóneas para la inversión privada y estimular la actividad económica. Al margen del cuestionamiento sobre el alcance de esta política de inversión, sigue tomándose como referencia este criterio para evaluar la contribución de los gobiernos al crecimiento económico de su territorio y es esencial en cuanto a su contribución en el proceso de convergencia económica de los Estados miembros. No podemos obviar que en torno al $30 \%$ del presupuesto de la propia UE se destina a los fondos estructurales, cuya finalidad es financiar las políticas orientadas a la cohesión económica y social de Europa.

Ya hemos señalado que las causas de la crisis no son exclusivamente financieras, sino que son necesarias reformas estructurales en las economías nacionales que en buena medida exigirán inversiones importantes. Los datos muestran que el volumen total de inversión en la UE ha experimentado una fuerte caída como consecuencia de la recesión de 2008. Ese resultado es esperable en la medida en que el coste político de reducir el gasto en inversión es menor que el coste político derivado de una disminución en la provisión de bienes y servicios a los ciudadanos. La reducción de este capítulo es, además, muy evidente en los Estados beneficiarios de las ayudas financieras del FEEF o del MEDE, como muestra el gráfico 3.

mismo año 2013, un 3,4\% del PIB para España, un $4 \%$ para Grecia, un 4,3\% para Portugal y un $4,5 \%$ para Irlanda; todos ellos muy por encima de la media UE-18, que se sitúa en un $2,9 \%$.

55 Eurostat (2015c). 


\section{Gráfico 3. Evolución de la inversión pública en Irlanda, España, Chipre, Portugal y Grecia}

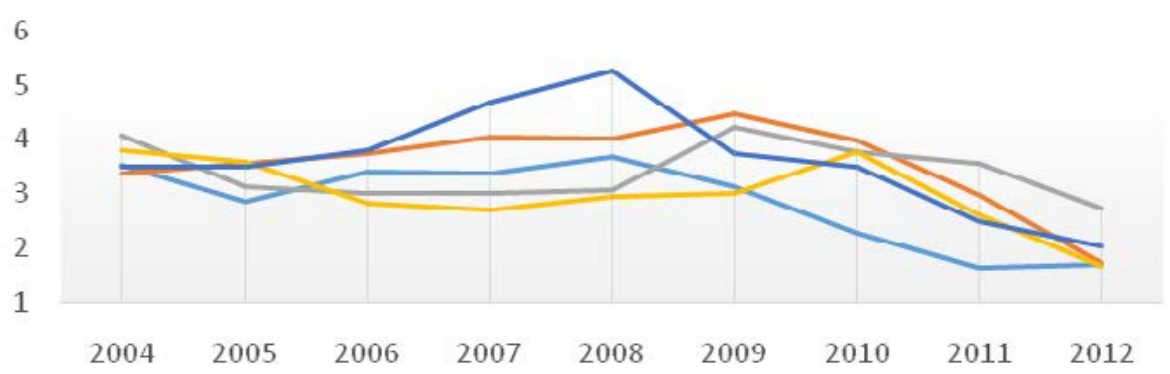

Fuente: elaboración propia a partir de Eurostat (2016a).

Cabe inferir que la disciplina presupuestaria exigida a estos Estados ha supuesto la reducción de la inversión pública, lo que dificulta, si no compromete seriamente, la realización de las reformas estructurales que deberían abordar para asegurar su crecimiento económico. La reducción de la inversión pública limita y minora también los efectos de la privada - hogares y empresas-, cuya caída refleja la pérdida de confianza en la economía y las dificultades para acceder a la financiación ${ }^{56}$. Se trata de un problema no menor, agravado por la regulación aprobada para los Fondos Estructurales del periodo vigente (2014/2020), que vincula la recepción de los mismos a la mejora de la gobernanza europea y al cumplimiento de los objetivos de estabilidad presupuestaria. Las reformas requieren financiación, de la que algunos Estados no pueden disponer sin incrementar su endeudamiento, y si no aportan esta financiación no pueden acceder a los fondos comunitarios para abordar dichas inversiones. Con la finalidad de superar esta restricción se instrumenta el European Fund for Strategic Investments — conocido como Plan Juncker—, que supone un intento de proveer de financiación adicional procedente del sector privado a los Estados en dificultades ${ }^{57}$.

56 Eurostat (2013: 49).

57 DOUE L 169/1 (2015): Reglamento UE 2015/1017, del Parlamento Europeo y del Consejo, de 25 de junio de 2015, relativo al Fondo Europeo para Inversiones Estratégicas, al Centro Europeo de Asesoramiento para la Inversión y al Portal Europeo de Proyectos de Inversión. De manera muy sucinta, el Plan Juncker pretende captar capital del sector privado para financiar inversiones públicas y facilitar la aportación de recursos propios de los Estados para estos proyectos. Una crítica 
Otro concepto de gasto de gran importancia en los últimos años es la carga financiera soportada por los Estados con alto endeudamiento: Grecia, Italia, Portugal, Chipre, Irlanda y Bélgica superan el $100 \%$ de su PIB. En 2014, la media de la zona euro alcanza el 92,1\% del PIB, mientras que la UE-28 se sitúa en el 86,8\%, incrementándose, en ambos casos, respecto al dato de 2013. De hecho, la evolución de la deuda pública (tabla 1) es similar en los dos grupos de Estados, con incrementos por encima de 7 puntos del PIB, lo que una vez más muestra la repercusión de la moneda única en el déficit financiero de los Estados de la UEM. Según datos de Eurostat ${ }^{58}$, la deuda pública aumentó en veinte Estados, de los cuales dieciséis comunicaron un porcentaje de deuda superior al $60 \%$ del PIB en 2014. Los incrementos más importantes se produjeron en Eslovenia (10,6 puntos) y Bulgaria $(9,3)$, mientras que Irlanda, Polonia, Chequia, Alemania, Malta, Eslovaquia, Hungría y Luxemburgo redujeron su deuda pública. Los datos anteriores toman una dimensión más precisa a la vista de la tabla 3, en la que presentamos el endeudamiento de la UE-28 y de la zona euro, desagregando para cada Estado miembro y considerando la variación experimentada en los dos últimos años del periodo considerado.

Tal como como podemos contrastar, la mayoría de los Estados muestran un desbalance en sus cuentas no financieras, destacando los que superan el $3 \%$ marcado como referencia, entre los se encuentran varios de los países del sur de Europa, entre ellos España.

A modo de cierre de esta sección podemos afirmar que los Estados miembros han actuado en los dos elementos del presupuesto para tratar de equilibrar sus cuentas: incrementando el ingreso y reduciendo su gasto consolidado, casi con la misma intensidad. Considerando la situación de crisis económica en la que han realizado este esfuerzo, las decisiones adoptadas adquieren mayor importancia porque son contrarias al efecto que el ciclo económico genera sobre ingresos y gastos públicos. Como hemos visto, el incremento de los ingresos tiene su origen en un aumento de la presión fiscal a la que se someten los factores menos móviles de la economía, fundamentalmente, el trabajo. Esta situación, como ya hemos descrito, genera problemas

sustancial al planteamiento de este instrumento es que no garantiza que afluya más financiación a los Estados más necesitados de inversiones estructurales, sobre todo porque el objetivo de los agentes privados — que serán los que aporten un mayor volumen de recursos - es la rentabilidad que dicha inversión genere. En este punto, cuestiones como la mera situación central o periférica de un país afectará a la rentabilidad esperada de sus proyectos y determinará una posición de ventaja o no en la captación de dichos fondos.

Eurostat (2016a). 
LA GOBERNANZA ECONÓMICA DE LA UNIÓN DURANTE LA CRISIS: CONSECUENCIAS... 179

Tabla 3. Endeudamiento de la UE/ UEM y Estados miembros (2013 y 2014)

\begin{tabular}{lcclcc}
\hline & & & \multicolumn{1}{c}{ 2013 } & \multicolumn{2}{c}{$\mathbf{2 0 1 4}$} \\
\hline \multicolumn{1}{c}{ EU-28 } & & & $-\mathbf{3 , 3}$ & \multicolumn{2}{c}{$\mathbf{- 3 , 0}$} \\
\hline EA-19 & & & $\mathbf{- 3 , 0}$ & \multicolumn{2}{c}{$\mathbf{- 2 , 6}$} \\
\hline Dinado miembro & $\mathbf{2 0 1 3}$ & $\mathbf{2 0 1 4}$ & Estado miembro & $\mathbf{2 0 1 3}$ & $\mathbf{2 0 1 4}$ \\
\hline Luxemburgo & $-1,3$ & 1,5 & Italia & $-2,9$ & $-3,0$ \\
\hline Estonia & 0,7 & 1,4 & Bélgica & $-2,9$ & $-3,1$ \\
\hline Alemania & $-0,1$ & 0,7 & Polonia & $-4,0$ & $-3,3$ \\
\hline Lituania & $-0,1$ & 0,3 & Finlandia & $-2,5$ & $-3,3$ \\
\hline Rumanía & $-2,6$ & $-0,7$ & Grecia & $-12,4$ & $-3,6$ \\
\hline Letonia & $-2,2$ & $-1,4$ & Irlanda & $-5,7$ & $-3,9$ \\
\hline Suecia & $-0,9$ & $-1,5$ & Francia & $-4,1$ & $-3,9$ \\
\hline Rep. Checa & $-1,4$ & $-1,7$ & Eslovenia & $-15,0$ & $-5,0$ \\
\hline Malta & $-1,3$ & $-1,9$ & Croacia & $-5,4$ & $-5,6$ \\
\hline Holanda & $-2,6$ & $-2,1$ & Reino Unido & $-5,7$ & $-5,7$ \\
\hline Hungría & $-2,4$ & $-2,4$ & Bulgaria & $-0,8$ & $-5,8$ \\
\hline Austria & $-2,5$ & $-2,5$ & España & $-6,9$ & $-5,9$ \\
\hline Eslovaquia & $-1,3$ & $-2,7$ & Portugal & $-4,8$ & $-7,2$ \\
\hline & $-2,6$ & $-2,8$ & Chipre & $-4,9$ & $-8,9$ \\
\hline
\end{tabular}

Fuente: elaboración propia a partir de Eurostat (2016a).

importantes de equidad en el sistema y también de eficiencia, empeorando la competitividad de la UE frente al exterior, y la posición relativa de ciertos países — los de mayor déficit — frente a otros con mejor fiscalidad dentro de la propia Unión. Esta pérdida se ve agravada por la presión de la carga financiera del endeudamiento y los gastos sociales asumidos, que absorben una parte cada vez mayor del gasto público total. La consecuencia más inmediata es la reducción del gasto en las inversiones que las economías requieren para poder mejorar su competitividad. 


\section{CONCLUSIÓN: LA GOBERNANZA ECONÓMICA DE LA UNIÓN DURANTE LA CRISIS HA DEBILITADO LA INTEGRACIÓN POLÍTICA Y ECONÓMICA DE LA UNIÓN}

En nuestra opinión, no se equivocan aquellos que apuntan al momento existencial que atraviesa actualmente la Unión. Esta, durante la crisis, ha actuado básicamente para garantizar la solidez de la moneda y ello ha requerido profundizar en el proceso de integración económica. Se han articulado, en particular, iniciativas que se han traducido en un incremento de la presión impositiva y disminución del gasto público (austeridad) con el objetivo de alcanzar los objetivos de déficit y deuda públicos y así garantizar la estabilidad presupuestaria de la zona euro, presentada como condición inexcusable del correcto funcionamiento de la UEM. Sin embargo, el desarrollo de la gobernanza económica de la Unión durante la crisis, que ha pivotado fundamentalmente sobre dicha regla de la estabilidad presupuestaria, no ha conseguido el efecto deseado. El resultado ha sido, antes bien, una afectación, en términos negativos, sobre la naturaleza constitucional del proyecto y su sostenibilidad económica.

Los últimos desarrollos de la gobernanza económica en la Unión han alterado su arquitectura institucional, minimizando el rol de los canales comunitarios y fortaleciendo de forma evidente su sesgo intergubernamental, y esto se ha hecho, en general, sin compensar esta tendencia con un reforzamiento del papel de las instituciones representativas en el nivel nacional como instrumentos de control efectivo de lo que sus Ejecutivos hacen en las instituciones europeas. Por cierto, esta apuesta por el intergubernamentalismo nos recuerda el momento fundacional y la primera etapa de funcionamiento de las Comunidades, si bien con la diferencia fundamental de que la Unión, en aquella primera fase, ejercía competencias muy limitadas, y, además, los Estados miembros considerados individualmente mantenían el control del proceso. En la actualidad, decisiones importantísimas al respecto se han adoptado empleando el «método de la Unión» frente al «método comunitario» (se han concretado, pues, fuera del derecho de la Unión). Se ha fortalecido el papel decisor y supervisor de las instituciones de la Unión que representan el interés particular de los Estados miembros (Consejo Europeo y Consejo), que, asimismo, han visto cómo han emergido serios competidores, instituciones también de sesgo intergubernamental pero cuyas decisiones se refieren únicamente a los países de la zona euro (eurocumbres y Eurogrupo). Especialmente preocupante para los que apostamos por el proyecto político de integración constitucional de la Unión es el hecho de que las decisiones que emanan de estas instituciones continúan siendo dibujadas en términos básicamente intergubernamentales 
(atendiendo predominantemente a intereses nacionales en un marco donde, además, Alemania ha terminado por imponer su contrato social al resto de Estados provocando una abstracción peligrosa que no ha tomado en consideración los diversos contextos socioeconómicos de cada país ${ }^{59}$ ). La Comisión, la institución que debería funcionar articulando el interés general de la Unión, ha perdido mucho poder político durante el proceso, aunque desempeñe importantísimas funciones de supervisión sobre el cumplimiento de los compromisos de estabilidad presupuestaria asumidos por los Estados. Asimismo, no hay que olvidar que, de facto, se ha producido la «nacionalización» de dicha institución en la medida en que los países no han renunciado a la composición "cada Estado un comisario» y copan los puestos de importancia en su seno a través de personas afines a sus Ejecutivos. El Parlamento Europeo, la institución que debería funcionar representando y articulando los intereses plurales de la ciudadanía europea, desempeña un papel absolutamente marginal en este escenario supraestatal de negociación, decisión y supervisión de las políticas económicas que vinculan a los Estados miembros. Y, en definitiva, esta nueva tendencia en el sistema institucional decisional impide satisfacer los principios democráticos de publicidad y transparencia dificultando las posibilidades de fiscalización del poder, y, en su caso, la rendición de cuentas (especialmente preocupante en los casos de aquellos países en los que la asunción de la toma de decisiones por el nivel europeo en dichas instituciones, en la que se encuentran representados los Ejecutivos nacionales, no viene acompañada de un control parlamentario nacional efectivo) ${ }^{60}$.

Los hay que han interpretado este viraje hacia el intergubernamentalismo de la Unión como una solución necesaria para responder de forma ágil a los retos de la crisis. Ahora bien, una solución como esta, que quizá pudiera

59 Areilza (2014: 225-226).

60 En este sentido, Porras (2012: 165-166). En todo caso, abogar por una mayor intervención del Parlamento Europeo en este ámbito no impide tener en cuenta que son necesarios cambios en su organización y articulación interna para corregir las deficiencias de su funcionamiento. También resulta preciso generar una mayor motivación en la ciudadanía europea en lo relativo a la participación en los comicios europeos, que se ha ido reduciendo progresivamente desde las primeras elecciones hasta el día de hoy. Por otra parte, y desde el punto de vista del principio democrático, hay que tener en cuenta que los pesos y contrapesos en el ejercicio del poder democrático son menores en el plano europeo que en el plano nacional. En el plano europeo, por ejemplo, no existe el mismo control que en el plano interno puede ejercer la opinión pública, los partidos políticos y los medios de comunicación (Areilza, 2014: 44-46). 
llegar a justificarse en el corto plazo (aunque siempre, naturalmente, acompañada de un reforzamiento de la participación de las instituciones representativas del Estado), no es una solución neutral pues altera completamente el equilibrio institucional europeo y no se puede perpetuar en el tiempo en el contexto de una Unión que decide cada vez más, en ámbitos cada vez más importantes, y en la que determinados Estados pueden ver cómo salen adelante decisiones a pesar de su oposición frontal a las mismas. En un contexto como este, creemos que un reforzamiento intenso del papel de los Parlamentos nacionales no podría compensar la falta de legitimidad democrática en el nivel europeo, donde decisiones decisivas para la vida cotidiana de los ciudadanos se estarían adoptando de espaldas a los requerimientos básicos del principio democrático.

Desde el constitucionalismo, no podemos aceptar que este empujón en el proceso de integración se pueda producir a cualquier precio, y, en la actualidad, uno de los grandes retos que ha de afrontar la Unión tiene que ver con la tensión existente entre el constitucionalismo normativo y un intergubernamentalismo político que agrega preferencias de los Gobiernos nacionales para llegar a soluciones que pueden producir un perjuicio en los estándares constitucionales de la Unión (o alcanzarse a costa de los mismos) ${ }^{61}$. La reivindicación sobre una interpretación constitucional de la crisis económica y la imposibilidad de realizar una interpretación funcional de la democracia al servicio de intereses como la eficacia o la eficiencia económica —en todo caso también intereses legítimos- no son discutibles ${ }^{62}$. Las soluciones a una crisis de tal magnitud pasan por el avance hacia una mayor integración económica, bancaria, fiscal, pero ello debe venir necesariamente acompañado de una profundización en la Unión Política (no podemos continuar ahondando en la profundización de la integración económica de la Unión a costa de su integración política ${ }^{63}$. Urge renovar, ahora que el populismo antieuropeo todavía suena con baja intensidad — pero suena, jcuidado!- , la utopía europea a través de una necesaria legitimación de la misma. Por el contrario, la perpetuación de los modelos de funcionamiento de la Unión que se han impuesto en estos años de crisis es

\footnotetext{
Poiares (2010).

62 Balaguer (2013a: 452-454; 2013b).

63 En este sentido, entre muchos otros Chiti y Texeira (2013: 701 y 704-705), Torres (2013: 193-212), Menéndez (2012: 97), Areilza (2014: 227-236), Aguilar (2015: 134-135). Todavía pendiente de publicación, resulta interesantísimo el análisis que el profesor García Guerrero realiza sobre las consecuencias que las diferentes fases de la integración económica tienen para el principio democrático, al que van vaciando progresivamente de contenido (García Guerrero, en prensa).
} 
contraproducente y contraria a la reinvención de la integración basada en la idea de un poder europeo legítimo y limitado. Nos estamos refiriendo al "circuito cerrado" del modelo intergubernamental que domina la actuación de la Unión en dicho ámbito, ajeno a la transparencia y a la rendición de cuentas, pero también al modelo tecnocrático que la presenta como un proyecto vinculado a una cierta idea de despotismo ilustrado (otro asunto problemático al que deberíamos prestar más atención en nuestras investigaciones $)^{64}$.

Es por tanto evidente que la supervivencia del proyecto constitucional europeo no se puede asentar única y exclusivamente en una legitimación por resultados. Sin embargo, tampoco consideramos acertado pensar, ingenuamente, que los mismos son intrascendentes; más bien, constituyen un factor adicional de legitimación de este proyecto de integración europea.

A nuestro juicio, la regla de estabilidad presupuestaria es un trasunto de una programación adecuada de los ingresos y gastos públicos, y, por tanto, no debe cuestionarse tanto su aplicación como su concreta configuración, el momento e intensidad con que se impone al conjunto de la Unión, $y$, en concreto, a los Estados que presentan un elevado déficit y que no disponen de recursos para poder reestructurar su economía (que se ven abocados a tomar decisiones contrarias a lo que su situación económica demanda con los efectos perversos que hemos puesto de relieve). En estos casos, en particular, un planteamiento estricto de la regla de estabilidad impedirá que actúen los estabilizadores automáticos del presupuesto, que son los instrumentos que permiten adecuar la actuación fiscal de un gobierno al ciclo económico, compensando con el presupuesto los desequilibrios del mercado en

64 Aunque no ha sido objeto de este estudio, creemos que debemos apuntar la tesis de Areilza Carvajal, que compartimos plenamente, según la cual la dicotomía intergubernamentalidad/supranacionalidad no es suficiente para entender el desarrollo actual de la Unión. El enfoque que pone el acento únicamente en el análisis de la evolución de los equilibrios entre los Estados miembros y la Unión es insuficiente y hay que completarlo con el enfoque que hace referencia a la «infranacionalidad» en la configuración de las políticas de la Unión. El autor, con el término «infranacionalidad», hace referencia al funcionamiento marcadamente tecnocrático que se produce en el seno de la Unión; al protagonismo adquirido por actores expertos en determinadas materias que no necesariamente actúan atendiendo a intereses nacionales y/o europeos. Y propone, habida cuenta de que cierto funcionamiento tecnocrático es inevitable, que se trabaje por introducir transparencia y rendición de cuentas en dicho funcionamiento (recordando que para ello no hacen falta reformas constitucionales) (Areilza, 2014: 78-85). 
un momento dado ${ }^{65}$; en tal situación, el presupuesto actúa como un freno en la recuperación de la economía, tanto por la incapacidad del sector público para abordar las inversiones necesarias como por la reducción de los recursos disponibles del sector privado, minorados a través de impuestos elevados.

La única opción actualmente a disposición de los Estados para reducir la presión fiscal e incrementar la renta disponible de los agentes económicos privados pasa por una severa restricción del gasto social que permita equilibrar el resultado final del presupuesto. Una decisión de este tipo no puede adoptarse sin asumir el elevado coste social que supondrá, en especial para los Estados con mayores problemas de déficit, sin pasar además por alto los graves problemas de legitimidad que ello comporta.

Como hemos mostrado, la asimetría en la respuesta de cada economía a la crisis tiende a mantenerse en el tiempo, con evoluciones dispares ante la imposibilidad del control de la moneda. La política regional europea, que junto a la disciplina presupuestaria permitieron cierta sincronización del ciclo económico de los Estados de la Unión Monetaria, no es capaz de asegurar la corrección de los desequilibrios que provocó la crisis. En su diseño y formulación actual, los fondos estructurales no pueden responder a las necesidades de financiación que requieren los problemas coyunturales que han aparecido ni, lo que es más relevante, a la corrección de las deficiencias estructurales que impiden la convergencia económica. Así, observamos que el criterio de reparto es el mismo que el previsto con anterioridad a la crisis, sin considerar la situación de Estados que presentan un grave deterioro de sus índices socio-económicos y que, por efecto de la incorporación de Estados de menor renta per cápita, han dejado de percibir financiación comunitaria a través de estos fondos. Además, pese a que el volumen de recursos del presupuesto de la UE que absorben los fondos estructurales es elevado, no ha experimentado un cambio significativo respecto del periodo anterior y ello pese al aumento de las disparidades interestatales que se constatan. Por

65 En esencia, son mecanismos que permiten retirar renta en momentos de crecimiento e incrementarla en situaciones de crisis. Un estabilizador básico en el ámbito de los ingresos públicos es la progresividad del impuesto sobre las rentas personales: si la capacidad económica de un contribuyente se incrementa su carga fiscal será mayor que el crecimiento de su renta — de esta manera, el Estado retira recursos del mercado-. Por la vía del gasto, la partida más relevante son las transferencias sociales que compensan situaciones en las que el individuo no genera renta suficiente para su subsistencia: a través de estas subvenciones, los sujetos disponen de recursos que emplearán en el mercado, incentivando el crecimiento de la demanda agregada en momentos de caída del ciclo económico. 
último, la inclusión de criterios de eficiencia en su reparto y la vinculación del derecho a su percepción al cumplimiento de los objetivos de estabilidad presupuestaria suponen un riesgo adicional para aquellos países con mayores problemas de déficit público, a lo que hay que añadir las dificultades que estos mismos Estados tienen para poder disponer de la financiación propia obligatoria que deben aportar a los proyectos de inversión que se financian a través de estos fondos. La Comisión es consciente del problema cuando crea el European Fund for Strategic Investments, pero ni el volumen de recursos que aporta ni los criterios de reparto utilizados garantizan que puedan financiarse las inversiones que algunas economías requieren para retomar el proceso de convergencia.

Pese a estas disfunciones, la Unión Europea sigue siendo un proyecto que se mantiene y cuya importancia es crucial en el entorno europeo. Se avance o no en la integración política (algo que consideramos absolutamente necesario), la ventaja de la agrupación para hacer frente a la competencia de otras áreas -Estados Unidos, el sudeste asiático y, especialmente, China- es casi la única oportunidad de crecer económicamente en un entorno de competencia global. El crecimiento económico del área y el de las regiones de menor nivel de desarrollo ha sido el sostén del proyecto europeo durante mucho tiempo. Pero la regla de estabilidad, tal como se ha configurado en su aplicación en un periodo de crisis económica, ha generado una pérdida de convergencia de las economías y de la cohesión del territorio con el consiguiente riesgo de desintegración. En nuestra opinión, la Unión debe dar mayor relevancia a los criterios de solidaridad interterritorial y cohesión para poder garantizar su propia pervivencia, y como propuesta planteamos no solo la revisión de la temporalidad impuesta por aplicación estricta de la regla de estabilidad sino también la reforma de los criterios de reparto de los fondos estructurales para permitir a los Estados con más déficit la financiación de las reformas que sus economías requieren para volver a ser competitivas.

\section{Bibliografía}

Aguilar Calahorro, A. (2015). La posición del Tribunal de Justicia de la Unión Europea en relación a las medidas adoptadas ante la crisis económica. En F. Balaguer Callejón, M. Azpitarte Sánchez, E. Guillén López y J. F. Sánchez Barrilao (eds.). El impacto de la crisis económica en las instituciones de la UE y los Estados miembros. Cizur Menor, Navarra: Universidad de Granada-Thomson Reuters Aranzadi.

Areilza Carvajal, J. M. de (2014). Poder y Derecho en la Unión Europea. Pamplona: Aranzadi. Azpitarte Sánchez, M. (2014). Los confines de la democracia y la solidaridad. A propósito de las decisiones del Tribunal Constitucional Federal alemán de 14 de enero y de 18 de 
marzo de 2014, que enjuician el marco jurídico-supranacional de las políticas de rescate. Revista Española de Derecho Constitucional, 101, 301-336.

Balaguer Callejón, F. (2012). Crisi economica e crisi costituzionale in Europa. En B. Andò e F. Vecchio (cur.). Costituzione, globalizzazione e tradizione giuridica europea. Padova.

- (2013a). Crisis económica y crisis constitucional de Europa. Revista Española de Derecho Constitucional, 98, 91-107.

- (2013b). Una interpretación constitucional de la crisis económica. Revista de Derecho Constitucional Europeo, 19, 449-454.

Banco Central Europeo. (2016). Statistisc. Goverment Finances. Disponible en: https://www. ecb.europa.eu/stats/gov/html/index.en.html.

Bar Cendón, A. (2012). La reforma constitucional y la gobernanza económica de la Unión Europea. Teoría y Realidad Constitucional, 30, 59-87.

Benvenuti, M. (2015). Le misure anticrisi adottate dall'Unione Europea: uno sguardo d'insieme (tra continuità delle scelte istituzionali, integrazione negativa e decostituzionalizzazione del diritto sovranazionale). En F. Balaguer Callejón, M. Azpitarte Sánchez, E. Guillén López y J. F. Sánchez Barrilao (eds.). El impacto de la crisis económica en las instituciones de la UE y los Estados miembros. Cizur Menor, Navarra: Universidad de Granada-Thomson Reuters Aranzadi.

Carrera Hernández, F. J. (2013). Nuevos instrumentos para la gobernanza económica de la Unión Europea: el procedimiento de prevención y corrección de los desequilibrios macroeconómicos-PMD. Revista de Derecho Comunitario Europeo, 44, 63-100.

Chiti, E. y Teixeira, P. G. (2013). The constitutional implications of the European responses to the financial and public debt crisis. Common Market Law Review, 50, 683-708.

Closa Montero, C. J. (2014). Los cambios institucionales en la gobernanza macroeconómica y fiscal de la Unión Europea: hacia una mutación constitucional europea. Revista de Estudios Políticos, 165, 65-94.

Comisión de las Comunidades Europeas. (2016). Propuesta de Directiva del Consejo que modifica la Directiva 2011/16/UE en lo que respecta al intercambio automático obligatorio de información en el ámbito de la fiscalidad. COM, (2016) 25 final, 2016/0010 (CNS).

Craig, P. (2014). Economic governance and the euro crisis: Constitutional architecture and constitutional implications. En M. Adams, F. Fabbrini y P. Larouche (eds.). The constitutionalization of European budgetary constraints. Disponible en: https://doi.org/10.2139/ ssrn.2433071.

Elías Méndez, C. (2015). El papel de las Instituciones europeas ante la crisis económica: Banco Central Europeo, Consejo Europeo, Consejo de Europa, Comisión Europea y Parlamento Europeo. El impacto de la crisis económica en las instituciones de la UE y los Estados miembros. Cizur Menor, Navarra: Universidad de Granada-Thomson Reuters Aranzadi.

Esparza Aroz, M. (2012). El nuevo marco de la estabilidad presupuestaria en España. Asamblea. Revista Parlamentaria de la Asamblea de Madrid, 26, 153-202.

Eurostat (2013). Sustainable development in the European Union. 2013 monitoring report of the EU sustainable development strategy. Disponible en: http://ec.europa.eu/eurostat/documents/3217494/5760249/KS-02-13-237-EN.PDF 
- (2014). Eurostat News Release Euroindicators. 6/2014. Disponible en http://epp.eurostat.ec.europa.eu/cache/ITY_PUBLIC/2-23042014-AP/EN/2-23042014-AP-EN.PDF. (2015a). Europe in figures 2015: Eurostat yearbook. Eurostat Statistics Explained. Luxembourg: Office for Official Publications of the European Communities. Disponible en http://ec.europa.eu/eurostat/statistics-explained/index.php/Eurostat_ yearbook\#Related_Eurostat_publications.

- (2015b). Eurostat News Release Euroindicators. 186/2015. Disponible en http://ec.europa.eu/eurostat/documents/2995521/7036737/2-21102015-AP-EN.pdf/22806a483bb0-4eb0-b641-d420af17be5b.

- (2015c). Eurostat News Release, 122/2015. Disponible en http://ec.europa.eu/eurostat/documents/2995521/6899478/2-07072015-AP-EN.pdf/797f4af9-c37f-46318211-5dd0b32fcb31.

- (2015d). Eurostat News Release, 181/2015. Disponible en http://ec.europa.eu/ eurostat/documents/2995521/7034688/3-16102015-CP-EN.pdf/7d2bba5e-ad864237-b5cf-08a5407ed801.

- (2016a). Government finance statistics. Eurostat Statistics Explained. http://ec.europa. eu/eurostat/statistics-explained/index.php/Government_finance_statistics.

(2016b). Eurostat News Relase Euroindicators. 10/2016. Disponible en http://ec.europa. eu/eurostat/documents/2995521/7130733/2-15012016-BP-EN.pdf/2127ecab7177-4060-9528-c1d938a75718.

European Stability Mechanism (2014). Annual Report, 12. Disponible en http://www.esm. europa.eu/pdf/204204_ESM_RA_2014_web.pdf

Fasone, C. (2012). The struggle of European Parliament to participate in the new economic governance. European University Institute Working Papers, RSCAS 2012/45, Robert Schuman Centre for Advanced Studies, EUDO-European Union Democracy Observatory.

Fernández-Albertos, J. (2014). Lecciones de la crisis para el gobierno económico de Europa. Revista de Estudios Políticos, 165, 163-187.

Frosina, L. (2015). La costituzionalizzazione dei vincoli europei di bilancio. El impacto de la crisis económica en las instituciones de la UE y los Estados miembros. Cizur Menor, Navarra: Universidad de Granada-Thomson Reuters Aranzadi.

García Guerrero, J. L. (2016). Los derechos de ciudadanía en el nuevo orden mundial (en prensa). García Pechuán, M. (2015). El Consejo. En A. López Castillo (dir.). Instituciones y Derecho de la Unión Europea. Volumen I: Instituciones de la Unión Europea. Valencia: Tirant lo Blanch.

Jonung, L. y Drea, E. (2009). The euro: It can't happen, It's a bad idea, It won't last. US economists on the EMU, 1989-2002. Bruselas: Comisión Europea.

Kenen, P. (1969). The theory of optimum currency areas: An eclectic view. En R. Mundell y A. Swoboda (eds.). Monetary problems of the international economy, Chicago: The University of Chicago Press.

López Escudero, M. (2012). Las interminables reformas de la gobernanza económica de la zona euro. Revista General de Derecho Europeo, 27, 1-9.

Martín y Pérez de Nanclares, J. (2012). El nuevo Tratado de Estabilidad, Coordinación y Gobernanza en la Unión Económica y Monetaria: reflexiones a propósito de una peculiar reforma realizada fuera de los Tratados constitutivos. Revista de Derecho Comunitario Europeo, 42, 397-431. 
Martínez Alarcón, M. L. (2013). La estabilidad presupuestaria en el marco de la globalización: algunas reflexiones sobre su compatibilidad con la ideología jurídica del Welfare State. En F. Reviriego Picón (coord.). Constitución y globalización. Transformaciones del Estado constitucional. Zaragoza: Fundación Manuel Giménez Abad.

Martínez Lago, M. A. (2013). Constitucionalización del principio de estabilidad presupuestaria en la Unión Europea y en España. La Ley Orgánica de Estabilidad Presupuestaria y Sostenibilidad Financiera. En D. López Garrido (dir.). Reforma constitucional y estabilidad presupuestaria: el artículo 135 de la Constitución española. Madrid: CEPC.

Martinico, G. (2014). EU crisis and constitutional mutations: a review article. Revista de Estudios Políticos, 165, 247-280. Disponible en: https://doi.org/10.2139/ssrn.2439614.

Medina Guerrero, M. (2014). La constitucionalización de la regla del equilibrio presupuestario. Integración europea y centralización estatal. Revista de Estudios Políticos, 165, 189-210.

Menéndez Menéndez, A. J. (2012). La mutación constitucional de la Unión Europea. Revista Española de Derecho Constitucional, 96, 41-98.

(2015). Integración económica e integración política: presentación panorámica. En A. López Castillo (dir.). Instituciones y Derecho de la Unión Europea. Volumen I: Instituciones de la Unión Europea. Valencia: Tirant lo Blanch.

Miguel Bárcena, J. de. (2011). El gobierno de la economía en la Constitución Europea. Crisis e indeterminación institucional. Barcelona: J. M. Bosch editor.

Mundell, R. (1961). A theory of optimum currency areas. The American Economy Review, 51 (4), 657-665.

OCDE (2015). Aligning transfer pricing outcomes with value creation, Actions 8-10-2015, Final Reports, OECD/G20 Base Erosion and Profit Shifting Project, OECD Publishing, Paris. Disponible en: https://doi.org/10.1787/9789264241244-en.

Poiares Maduro, M. (2010). Passion and Reason in European Integration. Vortrag an der Humboldt-Universität zu Berlin am 10. Februar 2010.

Poli, T. M. (2015). Corti costituzionali e governance económica: democracia e diritti fondamentali nel turbine della crisi económica. En F. Balaguer Callejón, M. Azpitarte Sánchez, E. Guillén López y J. F. Sánchez Barrilao (eds.). El impacto de la crisis económica en las instituciones de la UE y los Estados miembros. Cizur Menor, Navarra: Universidad de Granada-Thomson Reuters Aranzadi.

Porras Ramírez, J. M. (2012). La arquitectura institucional de la Unión Europea. Consideraciones críticas tras la reforma del Tratado de Lisboa. Revista de Estudios Políticos, 156, 125-166.

Puetter, U. (2012). Europe's deliberative intergovernmentalism: The role of the Council and European Council in EU economic governance. Journal of European Public Policy, 19 (2), 161-178. Disponible en: https://doi.org/10.1080/13501763.2011.609743.

Ragone, S. (2015). La incidencia de la crisis en la distribución interna del poder entre parlamentos y gobiernos nacionales. En F. Balaguer Callejón, M. Azpitarte Sánchez, E. Guillén López y J. F. Sánchez Barrilao (eds.). El impacto de la crisis económica en las instituciones de la UE y los Estados miembros. Cizur Menor, Navarra: Universidad de Granada-Thomson Reuters Aranzadi.

Torres, F. (2013). The euro crisis, institutional change and political constraints. En B. de Witte, A. Héritier y A. H. Trechsel (eds.). The Euro crisis and the state of European Democracy. Florencia: European University Institute. 
Unión Europea (2014). Taxation trends in the European Union. Data for the EU Member States, Iceland and Norway. Statistical Books.

Von Bondandy, A. e Ioannidis, M. (2014). La deficiencia sistémica en el Estado de Derecho. Qué es, qué se ha hecho y qué se puede hacer. Revista de Estudios Políticos, 165, 19-64.

Weiler, J. H. H. (2011). The political and legal culture of European Integration. International Journal of Constitutional Law, 9 (3-4), 678-694. Disponible en: https://doi.org/10.1093/ icon/mor054. 